\title{
Arqueólogos (s)em fronteiras: o Projecto ANA-lise e o estudo do povoamento do Baixo Guadiana (Portugal e Espanha) entre os séculos VIII a.C. e I d.C. ${ }^{1}$
}

\section{Archaeologist with(out) borders: the ANA-lise Project and the study of Low Guadiana Valley's settlement (Portugal and Spain) from $8^{\text {th }} \mathrm{C}$. BC \\ to $1^{\text {st }}$ C. AD}

Recebido em: $15 / 08 / 2018$

Aceito em: 04/01/2019

Pedro Albuquerque ${ }^{2}$

Francisco José García Fernández ${ }^{3}$

\begin{abstract}
Resumo:
O estudo das fronteiras e dos territórios fronteiriços é um tema de investigação com repercussões evidentes no mundo actual, bem como uma oportunidade para desenvolver estratégias de turismo cultural e protecção do património cultural. Apresentam-se, neste trabalho, algumas questões sobre um projecto de investigação transfronteiriço ( $A N A$-lise/ $A N A$-lisis) que estuda o povoamento humano ao longo da bacia do Guadiana entre os séculos VIII a.C. e I d.C., bem como o papel do projecto no contexto de outras iniciativas na União Europeia. Apresentam-se, igualmente, alguns resultados preliminares de duas campanhas de prospecção que contribuíram para a elaboração de um tentame de síntese dos processos prévios à construção da fronteira política entre os países ibéricos com o Tratado de Alcañices (1297) e para uma reflexão sobre a necessidade de desenvolver estudos e estratégias de protecção e difusão do património cultural transfronteiriço.
\end{abstract}

Palavras-chave:Fronteiras, Património, Espanha-Portugal, Baixo Guadiana

\begin{abstract}
:
The study of Boundaries or Borderlands is a current theme of research and an opportunity to develop strategies for cultural tourism and for the protection of Cultural Heritage. This paper presents some questions about a Cross-border Reseach Program (ANA-lise/ ANA-lisis) that deals with the study of human settlement along the Guadiana Valley between the $8^{\text {th }}$ Century BC and the $1^{\text {st }}$ Century AD, as well as the project's role among others in the European Union's context; the results of two campaigns of field work and research are a stepping stone for a preliminary synthesis of the historical processes previous to the delimitation of the political boundary between Spain and Portugal with Alcañices' Treaty (1297), as well as for a global reflection about the need to study and protect the cross-border Cultural Heritage.

Keywords: Boundaries, Heritage, Spain-Portugal, Low Guadiana Valley
\end{abstract}

\footnotetext{
${ }^{1} \mathrm{O}$ presente artigo baseia-se na conferência proferida no Museu Nacional de Arqueologia em Lisboa no dia 7 de Abril de 2018, contando com a presença dos orientadores deste projecto de investigação financiado pela Fundação para a Ciência e Tecnologia (FCT), com o título O Baixo e Médio Guadiana (sécs. VIII a.C. - I d.C.): Percursos de uma fronteira (SFRH/BPD/110188/2015): Ana Margarida Arruda (Uniarq, Universidade de Lisboa), Francisco José García Fernández (Universidad de Sevilla) e José da Silva Horta (Universidade de Lisboa).

${ }^{2}$ Bolseiro de Pós-doutoramento. FCT, Uniarq, Universidad de Sevilla. albuquerque@us.es

${ }^{3}$ Professor Titular de Universidade. Universidad de Sevilla. fjgf@us.es
} 


\section{Introdução}

"[...] abolida a fronteira, não podemos continuar a pensar como se ela ainda lá estivesse mas sem estar! O que, de certa maneira, temos feito com as nossas preocupações de desenvolvimento transfronteiriço. Como, que sentido, se a fronteira já não existe?"

Gaspar, 1996, p. 405

Com o presente trabalho, pretendemos transmitir os desafios de um projecto de investigação (ANA-lise/ ANA-lisis), que se centra no estudo do povoamento do Baixo Guadiana entre os séculos VIII a.C. e I d.C., e que incide sobre uma região que inspira desde há bastantes anos justificadas preocupações por parte de intelectuais de diferentes disciplinas pela sua posição fronteiriça entre Espanha e Portugal. O estudo sistemático da fronteira luso-espanhola surge em 1983 no III Colóquio Ibérico de Geografia, quatro anos depois de um alerta lançado pelo organizador do primeiro encontro (Cabo, 1979). A realidade que Pintado e Barrenechea (1972) descreveram no início da década de 70 teve, nesse sentido, uma repercussão extraordinária pelo facto de ser o retrato de áreas deprimidas votadas ao esquecimento, onde o alistamento na Guarda Fiscal para a vigilância das fronteiras era uma das opções, e onde o contrabando (outra actividade para parte destas populações) era uma actividade quotidiana.

Poderíamos dividir o percurso dessas investigações em seis grandes fases. Da primeira delas, anterior a 1979, fazem parte alguns trabalhos, produzidos na Península lbérica, dedicados à caracterização das áreas fronteiriças. Na segunda (1979 e 1985), após a referida chamada de atenção (Cabo, 1979), assiste-se à multiplicação de estudos que reflectiram sobre a importância destas regiões e a necessidade de se promover o seu desenvolvimento a vários níveis, na antecâmara da entrada de Portugal e Espanha para a CEE em 1986. É neste ano que se inicia a terceira fase, que se prolonga até 1995, ano em que entrou em vigor a Convenção de Schengen nos países ibéricos (assinada em 1991), na qual se integra a implementação dos programas INTERREG I e II (1990-1993; 1994-1999, respectivamente). A quarta fase decorre entre 1995 e 2001, i.e., nos primeiros anos da integração no Espaço Schengen até a entrada de Portugal e Espanha na Moeda única. A quinta tem início em 2002, com a assinatura do Tratado de Valencia, e termina em 2010, com a criação da Euro-região Alentejo - Algarve - Andaluzia. Na última (2011actualidade) integram-se os mais recentes projectos desenvolvidos nos territórios fronteiriços (resumo em García Fernández et al. 2017a), em particular aquele que é discutido neste artigo.

A definição do estado da questão no último trabalho citado, bem como noutros anteriores (cf. Márquez Domínguez, 2012), permite compreender os principais propósitos do projecto, bem como as diversas lacunas de investigação e difusão patrimonial em geral, e arqueológica em particular, nos dois lados da fronteira (embora mais evidentes no lado espanhol). Apresentam-se, com isto, os primeiros resultados de uma análise do povoamento do Guadiana no período referido, bem como um conjunto de aspectos que podem vir a ser importantes para a valorização do património arqueológico fronteiriço, a partir de uma bibliografia que está longe de ser exaustiva.

\section{O Conceito de fronteira}

"A fronteira não é apenas o limite simbólico do território duma comunidade, unida por elementos comuns e interiorizados, em oposição ao Outro, mas é espaço de encontros, de influências, de relações, de trocas, de cumplicidades, de cooperações e solidariedades, pela situação nas extremas, nos confins dos territórios e soberanias nacionais."

Cavaco, 1997, p. 159

O termo fronteira invoca um amplo conjunto de situações que fazem dele uma representação sujeita a mudanças (de lugar, função e/ou dimensão), de acordo com as circunstâncias históricas que justificam o seu (des)uso. Esta variabilidade configura um conceito polissémico estreitamente relacionado com a própria noção de território como construção social, uma vez que pode significar um espaço de transição, de ruptura ou, simplesmente, um ponto de encontro neutro, onde termina 
a extensão de poder de uma entidade e começa outra (Caflisch, 1990). O excerto de Carminda Cavaco refere-se, obviamente, aos limites territoriais europeus em geral e à Raia luso-espanhola em particular, no contexto de uma convenção que aboliu as fronteiras internas do Espaço Schengen e reforçou as externas, o que permite desvalorizar, em boa medida, o sentido de ruptura que configura barreiras intransponíveis (embora quase sempre contornáveis) entre entidades que se vêem a si mesmas como possuidoras de um determinado território, sobre o qual exercem funções de soberania.

A percepção dos limites dos territórios nacionais conduziu à convicção, ainda anacrónica, de que o espaço de um "povo" é delimitado, no território e na essência, por "fronteiras naturais" (cf. Castro e González, 1989, p. 8), o que equivale a dizer que era a natureza, e não o Homem, que determinava os contornos de um espaço social (Sahlins, 1990, p. 1423). Esta condição atraiu as atenções da Geografia histórica, uma vez que permitia pensar o território numa perspectiva diacrónica e identificar fronteiras como "terras de ninguém", como linhas de demarcação ou como barreiras defensivas, inserindo-as e explicando-as nos mais diversos contextos históricos ou ideológicos como representações ou elementos estruturantes de discursos e projectos políticos (cf. Raffestin,1992; Cavaco, 1995b, p. 9; Ferreira, 1998, p. 338-339).

A fronteira é também o espaço periférico concebido a partir de um centro de poder. A sua função de defesa ou de delimitação do território configuram, porém, regiões com homogeneidade e dinâmicas próprias, em que a "linha" ou a "raia" são um elemento comum de identidade e não um marcador intransponível de separação. As áreas fronteiriças podem ser, portanto, regiões geográficas ou paisagens com uma humanização muito particular, mesmo quando são política e administrativamente separadas por uma linha de água como o Guadiana. Estas peculiaridades são evidenciadas pelas diversas etapas da formação, afirmação, consolidação e manutenção das fronteiras portuguesas, como demonstrou J. Cosme a partir de uma engenhosa leitura das fontes textuais (2014).

Partindo do que foi dito, é possível considerar também estes limites como marcadores de descontinuidades e justaposições, nem sempre perceptíveis na (con)vivência das comunidades, mas que por sua vez indicam convergências. É nesse sentido que se aplica a ideia de que as fronteiras podem ser espaços de transição, não só entre entidades políticas, mas também entre áreas culturais ou sistemas de organização diferentes, como se definiu num importante artigo (Castro e González, 1989, p. 10 - 11), ou mesmo entre modos de ocupação e/ou uso do espaço, - que pode não coincidir necessariamente com os limites estritamente políticos que uma comunidade define na sua percepção do território e na sua relação (obrigatoriamente variável) com os outros.

Estas relações obrigam, em muitos casos, a usar a fronteira como elemento de ruptura, ou melhor, como barreira que condiciona ou impede o acesso a um determinado território. Nestes casos, a linha de separação representa uma descontinuidade e exprime-se com um elemento físico (p.ex., uma muralha) destinado a reforçar o controlo dos limites de um território, o que reflecte um cenário conflitivo ou bélico em que a fronteira é um lugar de tensão (Cavaco, 1997), ou mesmo simbólico (monumentos, santuários, etc.). Aliás, em diversas fases construíram-se fortalezas e atalaias nas imediações de algumas povoações, o que se evidencia no Livro das Fortalezas de Duarte d'Armas, escrito em 1510. Porém, a falta de infraestruturas de comunicação pode conduzir a um efeito de ruptura ou barreira em territórios fronteiriços, sobretudo quando se trata de um rio como o Guadiana (Alves da Fonseca et al., 1996, p. 345).

Apesar destas funções de defesa, estes espaços são também lugares propícios ao desenvolvimento de cumplicidades. Nestes casos, a fronteira une comunidades e não as separa. Se atendermos à própria representação de Alcoutim pela pena de Duarte d' Armas, a imagem de delimitação e vigilância parece esbater-se no modo como os barcos são representados, i.e., num aparente vaivém entre as duas margens. Outro exemplo semelhante, embora mais recente, é a construção da Ponte Internacional de Espíndola, entre o Perú e o Equador em 1996, no contexto 
de uma tensão política entre os dois países. As necessidades de comunicação entre as comunidades da Sierra de Ayabaca (Perú) e o vizinho Cantão de Espíndola (Equador) conduziram à materialização de um projecto por iniciativa própria e independentemente de uma conjuntura política claramente negativa (Hocquenghem y Durt, 2002, p. 85-87). Não obstante, limitemo-nos a assinalar este aspecto sem entrar a fundo num tema que, apesar do seu interesse, é periférico em relação aos objectivos do presente trabalho.

Estas breves pinceladas sobre o conceito em apreço não se esgotam na sua vertente política. Vale a pena assinalar, embora muito de passagem, a importância dos elementos geográficos que configuram a mundivisão transmitida pelas fontes, o que, aliás, está bem patente na representação dos confins do mundo habitado, marcados pelo Estreito de Gibraltar, e que resultou até hoje numa abundante bibliografia (cf. Grau, 2012). Trata-se de imagens literárias que reflectem uma ideia de separação entre o conhecido e o desconhecido, onde existe um mais além que não se enquadra propriamente nas noções da koiné mediterrânea, representada como um mundo relativamente controlado (Janni, 1998).

No que diz respeito ao tema central deste projecto de investigação, sobressaem algumas contribuições sobre as várias acepções do conceito de "fronteira" no contexto da interpretação arqueológica. O interesse por estas questões tem no no 13 da revista Arqueología Espacial (1989) um importante ponto de inflexão, uma vez que colocou o tema na agenda da investigação e proporcionou uma oportunidade para a sua aplicação ao mundo pré-romano da Península lbérica (Grau, 2012, p. 23ss, com uma visão de síntese). Uma das principais interrogações é, essencialmente, a relação que estas imagens sociais do território mantêm com a própria noção de Estado ou outra entidade capaz de impor e manter os limites, bem como de controlar os meios de produção. Assim, a sua identificação no terreno converte-se num exercício intelectual de reconhecimento de antagonismos que justificariam a criação de fronteiras e determinados modos de socialização do espaço (Castro e González, 1989, p. 14-16). A paisagem converte-se, neste contexto, numa "entidad objetivamente organizada y culturalmente inventada" (Grau, 2012, p.24) que constitui um suporte fundamental para a criação e reforço de relações de pertença entre as comunidades que fazem uso do território (cf. Ruiz e Molinos, 2008).

Esta imagem permite encerrar a noção territorial e física do conceito e introduzir outro aspecto não menos relevante: a construção de fronteiras internas (simbólicas e intangíveis) que se projectam nas relações sociais enquanto instrumentos de diferenciação interpessoal e que podem testemunhar fenómenos de hibridação de comportamentos e práticas (Rizo e Romeo, 2006; Pech et al., 2009; cf. Grau, 2012; García Fernández, 2012, p. 721-722). Esta análise é especialmente importante em espaços fronteiriços ou em lugares propícios ao encontro de comunidades de origens diversas (p.ex., portos costeiros ou nos estuários dos grandes rios), como parece ser o caso de Castro Marim (Baesuris) ou de Mértola (Myrtilis), localizadas, respectivamente, na foz e no limite da navegabilidade do Guadiana (Albuquerque e García, 2017a, p. 177ss; Albuquerque et al., 2018, passim).

Teremos oportunidade de assinalar novamente este aspecto. Importa, por agora, passar para uma reflexão sobre a fronteira luso-espanhola como objecto de estudo e de interesse por parte da investigação, uma vez que justifica o papel que o projecto em apreço desempenha num contexto mais amplo no âmbito das iniciativas preconizadas nos territórios limítrofes dos países ibéricos.

\section{A fronteira luso-espanhola como objecto de estudo e interesse}

“Esperamos en el puerto la llegada de la lancha o, como se dice en Huelva, la 'canoa', en la que debíamos cruzar el estuario del río. Había por allí gente con paquetes atados con cuerdas, de mal disimulado contrabando, pescadores y patrones de barcas con gorra azul y carabineros armados con mosquetones. Tenía aquel puerto un aire de tiempo de guerra. [...] En el embarcadero de Vila Real de Santo Antonio, situada al otro lado del estuario, después de una maniobra 
bastante trabajosa para sacar el coche de la barca, pasamos la aduana portuguesa, no sin cierto papeleo que terminaba de ilustrar la ibérica peripecia del paso de la frontera".

Pintado e Barrenechea, 1972, p. 33

A viagem de A. Pintado e E. Barrenechea, vertida para uma magnífica obra, é um retrato pouco animador do abandono a que uma longa franja dos territórios espanhol e português havia sido votada, reflectindo um alarmante estado de marginalização do que A. Cabo chamou "gran bolsa de pobreza", que só no final dessa década foi alvo de uma verdadeira preocupação académica (Martín Lobo, 1978; Cabo, 1981; Campesino, 1987). A escassa produção bibliográfica até então dada à estampa era um claro testemunho de uma falta de interesse por este tema, exceptuando-se alguns trabalhos que pretendiam demonstrar a individualidade geográfica de Portugal através das suas "fronteiras naturais", assinados por autores como J. Leite de Vasconcelos, F.X. Silva Telles, A. Ferraz de Carvalho, A. Girão, O. Ribeiro e H. Lautensach (Garcia, 1997, p. 25-26; cf. Teles, 2015) antes dos anos 70, bem como outras contribuições de C. Cavaco e S. Daveau que não tiveram repercussão imediata no panorama científico ibérico (referências em López Trigal, 1984, p. 597-598; Campesino, 1987; Gaspar, 1987).

Fora da Península Ibérica, o tema das fronteiras já fazia parte de alguns debates científicos sobre a Geografia Política (cf. Guichonnet e Raffestin, 1974; Raffestin, 1974; Claval, 1974, com bibliografia anterior), o que se reflectiu na fundação, no Conselho da Europa, da Conferência Permanente dos Poderes Locais e Regionais (CPLRE). Nesta defendeu-se, em 1958, a importância das regiões naturais utilizadas como fronteiras enquanto potenciais pontos de contacto entre as nações. Em 1971, a Associação das Regiões Fronteiriças Europeias reforçou nesse sentido um conjunto de estratégias de cooperação (Cavaco 1995b, p. 13; 1996, p. 423-424; Ferreira, 1998, p. 341; Herrero, 2010, p. 10). Os processos de integração obrigaram, portanto, a olhar as regiões fronteiriças como áreas potencialmente marginalizadas, desvalorizadas e esquecidas pelos Estados europeus e como objecto de estudo social no que diz respeito ao efeito destas linhas divisórias sobre o quotidiano das populações (Raffestin, 1974, p. 12ss).

Como se comentou na introdução, o programa do I Coloquio Ibérico de Geografia (= CIG) em Salamanca (1979) confirma esta última afirmação pela absoluta ausência de comunicações sobre a fronteira luso-espanhola. Porém, no texto de apresentação das actas deste encontro, $A$. Cabo reclama para a comunidade científica ibérica uma reflexão conjunta sobre os problemas de fundo destas regiões, em grande medida pela sua relevância para as relações entre os dois países e pela necessidade de valorizar a fronteira mais além do seu carácter espacial, i.e., como uma entidade dinâmica e como resultado de relações sociais (Cabo, 1981, p. 11-12).

Alguns anos mais tarde, tanto a celebração do III CIG (Barcelona, 1983) como os Encuentros/ Encontros de Ajuda (Olivenza, 1985), marcaram um ponto de inflexão, com um conjunto importante de publicações que configuravam os alicerces da investigação sobre a fronteira como "factor geográfico" no âmbito da Geografia política e Regional (López Trigal, 1984; Campesino, 1987; Gaspar, 1987; Ferreira, 1998; sobre o papel do geógrafo como "intérprete" das fronteiras, cf. Guichard, 2000; Lois e Carballo, 2015, p. 193ss). Com isto, a investigação peninsular fazia, finalmente, eco dos referidos estudos europeus sobre o efeito da delimitação de fronteiras na organização do espaço, na economia e na vida das populações, e que havia conduzido à realidade confrangedora tão bem descrita por Pintado e Barrenechea (1972). Davam-se, portanto, os primeiros passos para passar da "fronteira - separação" a uma "fronteira - cooperação" no que dizia respeito, sobretudo, ao ordenamento territorial e ao aproveitamento de recursos naturais (López Trigal, 1984; Campesino, 1987), dos quais se destaca, precisamente, o empreendimento da barragem de Alqueva (Gaspar, 1987, p. 232).

Estes estudos acompanhavam o processo de integração de Portugal e Espanha na CEE em 1986, que por sua vez seria uma oportunidade para implementar projectos destinados a promover a fixação de população nas áreas fronteiriças através de programas de desenvolvimento regional 
(Campesino, 1987; Gaspar, 1987, p. 229-231; Barrientos, 1987) e de um necessário investimento na mobilidade (López Trigal, 1984, p. 601; Gaspar, 1987, p. 232). Após a consumação da integração em 1986 e de uma Cimeira Luso-espanhola (Lisboa, 2-3 de Novembro de 1988), que deu origem a um programa transfronteriço (Alves da Fonseca et al., 1996, p. 341-342), os três congressos seguintes (Coimbra, 1986; León, 1989; Porto, 1992) não contaram com sessões monográficas dedicadas ao assunto das fronteiras, embora a Directiva 2.058/88 da CEE determinasse que era "prioritária a intervenção nos espaços fronteiriços inter-comunitários, no âmbito de uma política global de desenvolvimento" (Junta de Andalucía, 1995, p. 11).

Assistiu-se, porém, na primeira metade da década de 90, a uma nova e importante etapa na intervenção e, consequentemente, na investigação sobre os territórios fronteiriços. Após a mencionada cimeira luso-espanhola celebrada em Lisboa, o programa INTERREG I foi introduzido entre 1990 e 1993 com o propósito de implementar medidas no sentido de melhorar o nível das condições de desenvolvimento, promover a fixação da população nas várias localidades, bem como a sua integração no Mercado Único Europeu (Cavaco, 1995b, p. 12; 1997, p.165; Junta de Andalucía, 1995; Alves da Fonseca et al., 1996, p. 342ss; Vega e Zoido, 1996, p. 450-452), sobretudo ao nível da rede viária (Vega e Zoido, 1996, p.444; Jacinto, 1996, p. 512-513) ${ }^{4}$. Ao mesmo tempo, deu início a novos estudos, realizados entre 1991 e 1992, sobre a situação em que se encontravam os territórios fronteiriços (Sánchez López, 1993, p. 13; Osuna, 1993).

Em 1991, a construção da Ponte Internacional do Guadiana (fig. 1) e a assinatura, por parte de Portugal e Espanha, da Convenção de Schengen, são dois momentos marcantes na aproximação dos dois países, fazendo antever a necessidade de uma mais estreita cooperação e coordenação (cf. Márquez Domínguez, 2001, p. 396-397). Até à entrada em vigor da Convenção em Março de 1995 e a consequente supressão definitiva dos controlos fronteiriços, o Governo português extinguiu a Guarda Fiscal (DL 230/ 93 de 25 de Junho), que mantinha desde 1974 funções de vigilância das fronteiras terrestes e marítimas (DL 171 e 215/74), deixando na paisagem vários postos, estrategicamente construídos em pontos de passagem do rio ${ }^{5}$. Nesse mesmo ano, aproveitando as novas oportunidades de interacção e cooperação, foi criado um projecto transfronteiriço - Anás - financiado pelo Fundo Europeu de Desenvolvimento Regional e pelo Fundo Social Europeu, com diversos âmbitos de acção (Márquez Domínguez, 2001).

A revitalização da discussão sobre as áreas fronteiriças dá-se, precisamente, no contexto da entrada em vigor da Convenção de Schengen e do INTERREG II, trazendo uma vez mais à colação a importância da cooperação que, nas palavras de J. Gaspar, "deveria sugerir um reforço das relações continentais com a concorrência de novas oportunidades para as áreas antes prejudicadas pela existência de fronteiras políticas" (Gaspar, 1996, p. 399).Tratava-se, portanto, de uma oportunidade para dar a estas regiões facilidades de desenvolvimento ou, pelo menos, um novo rumo através da discussão sobre o planeamento e de uma necessária participação dos geógrafos nesta reconfiguração (Cabero et al., 1995-1996; Cavaco, 1995a), bem como no "conhecimento e conceptualização da raia ibérica" (Lois e Carballo, 2015, p. 193). Por seu turno, outros especialistas conseguiram enriquecer o panorama com estudos que revelaram a extraordinária riqueza cultural destes territórios (cf. AAVV, 1996; Carrasco e Viudas, 1996).

A discussão sobre este tema complexo contava agora com um novo desafio, a saber, a criação de discursos e estratégias de intervenção sem fronteiras, ou pelo menos sem o efeito inibidor que estas tinham antes da entrada em vigor da Convenção de Schengen, como bem expôs J. Gaspar no excerto que serve de epígrafe a este artigo (Gaspar, 1996, p. 405). Estas novas

\footnotetext{
${ }^{4}$ Estas iniciativas cumpriam, no essencial, os objectivos 1 e 2 do programa: "promoção do desenvolvimento e ajustamento estrutural das regiões menos desenvolvidas"; "reconversão das regiões, regiões fronteiriças ou parte das regiões gravemente afectadas pelo declínio industrial" (Cavaco, 1995b, p. 12, n. 7). Sobre outros pactos ibéricos, veja-se Cavaco, 1995c, p. 2829.

${ }^{5}$ Estes imóveis têm vindo a ser requalificados nos últimos anos para fins turísticos, constituindo um testemunho da prática, no passado, do contrabando (Freire et al., 2009) e, no presente, do abandono destas áreas.
}

Revista Memória em Rede, Pelotas, v.11, n.20, Jan./Jun.2019 - ISSN- 2177-4129

periodicos.ufpel.edu.br/ojs2/index.php/Memoria 
estratégias traduziram-se, porém, no crescimento exponencial das áreas urbanas costeiras, acentuando alguns problemas que antes se registavam no interior (o êxodo, p.ex.), agora ainda mais isolado, com menos oportunidades e marginalizado como uma periferia nacional dentro de uma situação cada vez mais periférica dos países ibéricos na Europa (cf. Cavaco, 1995b, p.11; Márquez e Jurado, 2000), por sua vez reflectidos nos problemas demográficos à escala regional (entre outros, Felicidades e García, 2004).

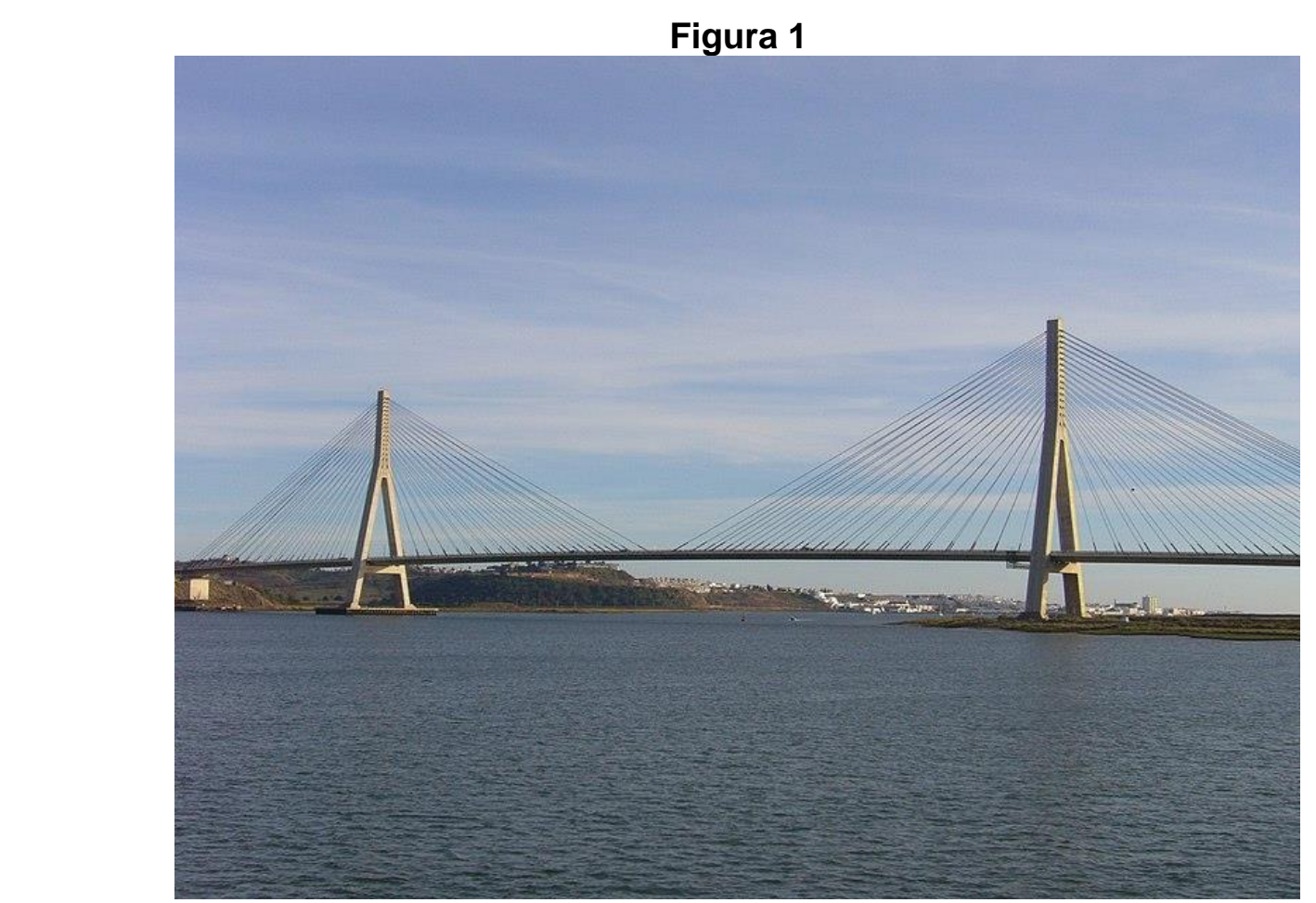

Ponte Internacional do Guadiana entre Portugal e Espanha, que atravessa o rio homónimo e une a Província de Huelva (Espanha) e a Região do Algarve (Portugal). Fotografía: RHaworth (Wikimedia Commons).

Os números do alto investimento na mobilidade entre vários pontos da Península (pouco visível nos territórios interiores; cf. Doctor, 2004, p. 118) contrastavam, por outro lado, com as acções de cooperação transfronteiriça no âmbito dos subprogramas do INTERREG (cf. López Trigal, 1996, p. 438-439; Castro, 2008, p. 13-19; Medeiros, 2009). Um dos reflexos mais evidentes destes programas é a criação, durante a década de 90 , das "comunidades de trabalho", antecessoras das Euro-regiões, iniciadas na Galiza e Norte de Portugal em 1991 e implementadas alguns anos mais tarde nas áreas de Andaluzia - Algarve (1995) e Andaluzia - Alentejo (2001), com o objectivo de gerir os fundos europeus destinados a estes territórios (cf. Herrero, 2010; Sobrido, 2004).

Este panorama revela a ausência de uma preocupação específica sobre a Cultura em geral (Amante, 2009, p. 161-162) e sobre o património histórico e arqueológico em particular, bem como sobre o aproveitamento turístico destas regiões no sentido da valorização das chamadas "paisagens culturais". O programa INTERREG II (1994 - 1999) procurava promover neste contexto o investimento de PME's nas áreas do "artesanato, turismo, desenvolvimento rural, ambiente e património, organizações profissionais, comerciais e associativas” (Cavaco, 1995b, p. 16), mas não se registaram muitas iniciativas nesse sentido. O projecto transfronteiriço "Al-Mutamid", que resultou na publicação do Catálogo de bienes de interés del entorno fronterizo del Bajo Guadiana (cf. Alves da Fonseca et al., 1996, p. 351; Castaño, 1997), constitui uma excepção. Esta obra, 
apesar de ser uma publicação bilingue, incidiu unicamente sobre os municípios raianos espanhóis (Ayamonte, Villablanca, San Silvestre de Guzmán, Sanlúcar de Guadiana e El Granado).

O início do século XXI foi também marcado pela implementação do INTERREG III (2000 2006) e pelo Tratado de Valencia em 2002, que dotou a cooperação transfronteiriça de um carácter jurídico (Herrero, 2010, p. 15; cf. Sobrido, 2004) e promoveu uma maior preocupação pelo património cultural como foco estratégico de cooperação, embora sem as consequências que seriam expectáveis nesta situação (Amante, 2009; García Fernández et al.,2017ª , p. 127-128) ${ }^{6}$. Efectivamente, são ainda poucas as iniciativas de índole cultural que poderiam revitalizar estas áreas e criar focos de atracção turística (Campesino, 2014; Campesino e Jurado, 2014; López Trigal, 2016, p. 191-192; Jurado e Pazos-García, 2018), tanto as que foram integradas no âmbito do INTERREG III (em particular, a Medida Estratégica 2.2), como no Programa de Cooperação Transfronteiriça Espanha - Portugal (POCTEP) 2007 - 20137. Encontra-se vigente, neste momento, o POCTEP 2014 - 2020, onde se nota uma ausência da Cultura entre os seus objectivos prioritários, apesar de incluir nos seus objectivos secundários a protecção e a valorização do património cultural e natural, assinalando a sua importância para a dinamização da economia local e regional ${ }^{8}$.

Um dos momentos mais relevantes desta fase é a assinatura do protocolo que deu origem à Euro-região Alentejo - Algarve - Andaluzia em 2010, que por sua vez substituiu os grupos de trabalho Alentejo - Andaluzia e Algarve Andaluzia (1995 e 2001, respectivamente). Tivemos oportunidade de comentar, noutra ocasião, os vários projectos e iniciativas transfronteiriços desenvolvidos no âmbito destes programas (García Fernández et al., 2017a, p. 129ss), o que dispensa um comentário mais extenso sobre cada um deles. Em jeito de síntese, podemos dizer que a criação de "itinerários" e, sobretudo, de "redes" com vocação paisagística e cultural, é a imagem de marca de algumas iniciativas financiadas por estes programas para o Guadiana enquanto eixo do território (Odyssea - SUDOE; ANDALBAGUA), embora seja evidente a escassa valorização de uma perspectiva histórica e arqueológica dos vários elementos patrimoniais que articulam a paisagem fronteiriça. O projecto UADITurS-Turismo Sustentável no Baixo/Bajo Guadiana, constitui uma excepção no contexto do POCTEP 2007 - 2013, uma vez que pretendia criar uma rota de centros de interpretação do território destinados aos visitantes e à população local. Por outro lado, a publicação de um mapa transfronteiriço à escala 1/50000 é um exemplo visível de uma iniciativa institucional que juntou centros de trabalho da Andaluzia (Instituto de Estadística y Cartografía de Andalucía, em colaboração com o Instituto Geográfico Nacional de Espanha) e de Portugal (Direcção - Geral do Território) ${ }^{9}$.

O projecto ANA-lise parte destes antecedentes e nasce com o intuito de valorizar a importância do património histórico e, em especial, do património arqueológico, enquanto elementos chave da paisagem de fronteira que permitem compreender, como recursos culturais, a compreensão da sua natureza, as suas dinâmicas e particularidades ao longo do tempo. Por outro lado, são determinantes para o desenvolvimento de estratégias de coesão das populações raianas, ao potenciar os traços particulares da sua identidade alicerçados num passado partilhado. Nesse sentido, o nosso projecto trata de abordar de forma transversal parte deste património, a saber, o que corresponde ao I Milénio a.C., momento em que o Baixo Guadiana passa a fazer parte da koiné cultural mediterrânea, tanto na sua dimensão geográfica (abarcando as duas margens e em estreita relação com o seu contexto paisagístico) como cronológica (analisando a evolução das sociedades que ocuparam estes territórios entre o final da Pré-história e a sua integração no Império Romano). Dizemos que adopta uma perspectiva transversal porque aspira

\footnotetext{
${ }^{6}$ Note-se, no entanto, a existência de profundas carências ao nível da mobilidade entre centros de menor dimensão no interior (Doctor, 2004; Márquez Domínguez, 2004).

${ }^{7} \mathrm{http}: / / 0713$.poctep.eu/index.php?modulo=presentacion\&id area=13 (cons. 29/03/2018).

${ }^{8}$ www.poctep.eu/es/2014-2020/presentación-2014-2020 (cons. 29/03/2018).

${ }^{9}$ Veja-se García Fernández et al., 2017a, com um resumo destas iniciativas.
} 
não só a incrementar o conhecimento sobre o período estudado, mas também a criar bases sólidas para a conservação e difusão desse património. Esta estratégia, cremos, fornece instrumentos necessários para a transformação dos recursos culturais em produtos culturais destinados a um perfil de turismo de fronteira cada vez mais incipiente, mas sobretudo a uma adequada transferência de conhecimentos para a população local.

\section{Arqueologia (s)em fronteiras: o projecto $A N A$-lise/ $A N A$-lisis}

Além das questões colocadas por um tema desta natureza, indubitavelmente actual e pertinente, o estudo das fronteiras pode ter, ainda, uma vertente histórica de extremo interesse, uma vez que a fronteira entre Portugal e Espanha sofreu poucas alterações desde o Tratado de Alcañizes (1297). O estatuto de linha divisória mais antiga e estável da Europa, apesar das necessárias matizações (Lois e Carballo, 2015, p. 199, com bibliografia) configura uma promissora via de investigação para o estudo das consequências da delimitação dos estados ibéricos no quotidiano das populações e para caracterizar, diacronicamente, as (im)permeabilidades dos espaços fronteiriços, inclusive antes da formação da fronteira histórica. Além disso, esta condição é idónea para criar estratégias de valorização deste património, posto que o percurso histórico dos estados separados por esta linha fronteiriça deixou vestígios na paisagem que podem fazer parte de roteiros culturais que contam uma história comum. Estes elementos constituem, como já se adiantou há mais de duas décadas, um potencial factor de desenvolvimento social, cultural e económico (cf. Alves da Fonseca et al., 1996, p. 347-349), que no caso em apreço têm no Baixo Guadiana um importante eixo (fig. 2).

Embora não se apresente nesta ocasião uma reflexão mais extensa sobre as fontes textuais e os seus problemas, é útil referir a aparição do antigo Anas nas obras de alguns autores clássicos. A menção mais antiga é a de Políbio, que afirmou (aparentemente sem mais informações) que o rio nascia na Celtibéria (Plb. 34.12 = Str. 3.2.11). Entre 104 - 101 a.C., Artemidoro pode ter referido o rio, mas a leitura do Papiro é, nesse sentido, problemática (Faria, 2006, p. 219; Albuquerque et al., 2018, p. 6ss, com bibliografia). Mais tarde, uma vez mais sem grandes desenvolvimentos, César apresenta o Guadiana como um referente do limite de acção militar $(B C, 38)$. Os textos posteriores não são, porém, mais esclarecedores, uma vez que se limitam a assinalar que esta linha de água separava a Bética da Lusitânia (Plin, Nat. 3.6: "amne Ana discreta"; Mela, 2,87: "illas fluvius Anas separat"). Estrabão afirma, por seu turno, que o rio delimita os territórios dos Célticos, Lusitanos (Str. 3.1.6) e da Turdetânia (3.2.1), o que parece confirmar que esses textos apresentam a tendência de usar estes referentes geográficos no ordenamento do seu discurso, sem que estas sejam um retrato fiel dessa organização (cf. España, 2017, p. 277ss) ${ }^{10}$.

Deixando de lado fontes posteriores sobre o uso do Guadiana como fronteira (cf. Garcia, 1997; Carriazo, 2002; Melón, 2014; Cosme, 2014, entre outros), que por si só merecem um tratamento monográfico, o projecto ANA-lise/ ANA-lisis procura,como se disse, estudar a história do rio antes da sua definição como linha de separação entre duas províncias, i.e., entre o séc. VIII a.C. e o séc. I d.C. (Albuquerque, 2017; Albuquerque e García, 2017b), com o intuito de colmatar algumas lacunas de investigação.

A condição fronteiriça do Guadiana e zonas adjacentes condicionou o modo como o rio foi visto pela investigação arqueológica e histórica, uma vez que esta se desenvolve dentro dos limites nacionais e acabou por considerar, logicamente, o Guadiana como uma periferia. Além disso, a falta de iniciativas ou de projectos nas áreas interiores do Guadiana justifica a escassez de dados arqueológicos reconhecidos na margem esquerda (i.e., espanhola) quando comparamos essa realidade com a margem direita, onde se registaram algumas intervenções de grande importância (p.ex.a construção da barragem de Odeleite ou a Estrada Municipal M507, que liga esta localidade

\footnotetext{
${ }^{10} \mathrm{~A}$ questão da associação entre a margem esquerda (Bética) e a direita (Lusitânia) revela que o rio não seria um elemento tão claro de separação (cf. Albuquerque et al., 2018).
} 
a Alcoutim) para a identificação de vestígios arqueológicos, ou inclusive para o desenvolvimento de outras actividades arqueológicas (Cardoso e Gradim, 2011).

Figura 2

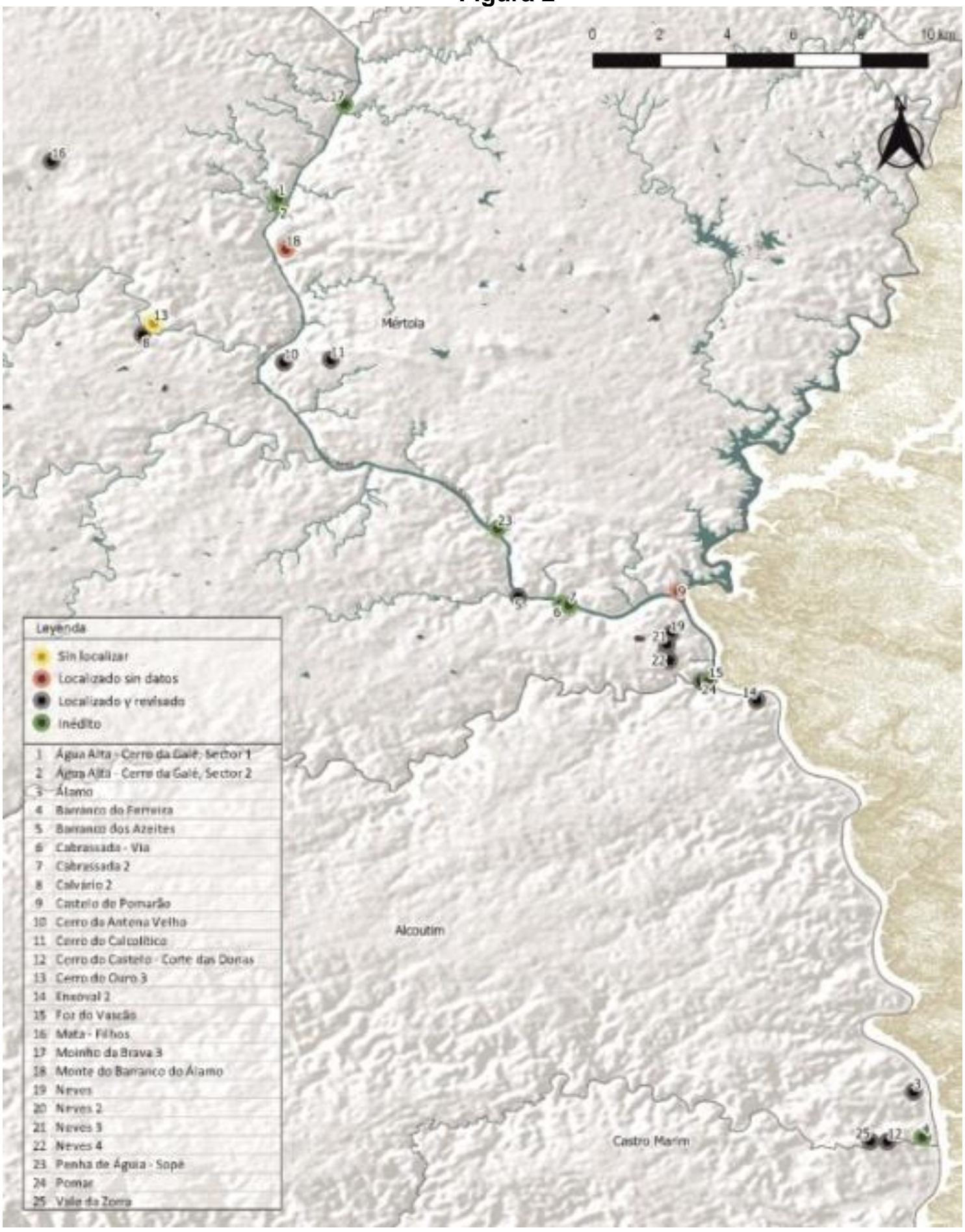

Resultados das prospecções levadas a cabo nos Concelhos de Mértola e Alcoutim (2016 e 2017). Distribuição dos sítios revistos e novas localizações.

Revista Memória em Rede, Pelotas, v.11, n.20, Jan./Jun.2019 - ISSN- 2177-4129 
Assim, à já assinalada necessidade de valorização do património cultural fronteiriço em projectos de cooperação entre os dois países, acrescenta-se a importância do desenvolvimento de novos trabalhos de investigação ao longo do Guadiana. Estes podem permitir não só o enriquecimento do catálogo de sítios arqueológicos conhecidos, mas também uma caracterização da longa história de ocupação dos territórios adjacentes ao rio. Neste sentido, a valorização da análise do leito do rio em detrimento do estudo regional (em que este é, como se disse, uma periferia) revela-se de grande utilidade para a criação de estratégias de cooperação transfronteiriça. No entanto, como já tivemos oportunidade de referir noutra ocasião (García Fernández et al., 2017a), existem, ainda, algumas carências ao nível do desenvolvimento de trabalhos arqueológicos nestas circunstâncias, tanto no que diz respeito às diferentes legislações patrimoniais ${ }^{11}$, como à inexistência (ou tratamento insuficiente) de um sistema cartográfico de referência compatível entre os dois países (Felicidades, 2016), para dar apenas dois exemplos mais evidentes.

Apesar destas dificuldades, que esperamos superar em breve, foi até agora possível realizar duas campanhas de prospecções arqueológicas (2016 e 2017) nos municípios portugueses de Mértola e Alcoutim, com o apoio de entidades locais (Mértola: Campo Arqueológico e Câmara Municipal; Alcoutim: Câmara Municipal) e com a participação de arqueólogas dos dois municípios (respectivamente, $\mathrm{M}^{\mathrm{a}}$ de Fátima Palma e A. Gradim). O objectivo destas campanhas, como se deixou antever, foi a caracterização do povoamento humano ao longo do Guadiana durante o período tratado neste projecto, o que levou a incidir sobre diversos tipos de lugar que poderiam fornecer informações relevantes para a análise da projecção da construção de fronteiras no território:

1. Desembocaduras de afluentes do Guadiana e pequenas enseadas com potencialidade portuária

2. Cerros com comunicação visual nas duas margens do rio

3. Áreas cujo topónimo pode indicar a presença de vestígios arqueológicos ou lugares de vigilância

4. Áreas de acesso privilegiado a matérias - primas

5. Vaus e pontos de passagem do rio (p.ex., nos lugares onde se implantaram casas dos guardas florestais

6. Pontos elevados com fácil acesso ao rio

7. Relocalização de sítios catalogados e prospecção de áreas adjacentes

O estudo territorial foi, por sua vez, complementado com a interacção entre este projecto e outro, coordenado por um de nós (FJGF), que incide sobre o estudo dos materiais arqueológicos exumados há poucos anos na área de expansão da biblioteca de Mértola (cf. Palma, 2009; García Fernández et al., 2017b; Albuquerque e García, 2017b). Estes trabalhos permitem a criação de uma sequência de referência para os materiais arqueológicos identificados ao longo do Guadiana e, consequentemente, a interpretação da relação entre Mértola (localizada no final do troço navegável do rio) e outros arqueossítios. Além disso, torna-se também necessária uma comparação com outras realidades do antigo Anas, nomeadamente Castro Marim e Ayamonte, ambos localizados na foz.

Até ao momento, não se prospectaram as áreas correspondentes aos termos municipais de Castro Marim (Portugal), Ayamonte, Sanlúcar de Guadiana e El Granado (Espanha), prevendo-se a realização de novas campanhas em 2019. Os resultados dessas primeiras prospecções fecham

\footnotetext{
${ }^{11}$ Isto reflecte-se, p.ex., nos pedidos de autorização e relatórios de trabalhos arqueológicos, que se entregam com diferenças a cada uma das entidades dos dois países (Junta de Andalucía, do lado espanhol, Direcção - Geral do Património Cultural, do lado português).
}

Revista Memória em Rede, Pelotas, v.11, n.20, Jan./Jun.2019 - ISSN- 2177-4129

periodicos.ufpel.edu.br/ojs2/index.php/Memoria 
o primeiro ciclo de trabalhos, centrado até ao momento na parte alta do Baixo Guadiana, no qual o projecto de investigação adquire, finalmente, uma dimensão transfronteiriça.

\section{O povoamento do Baixo Guadiana (sécs. VIII a.C. - I d.C.): velhos e novos dados}

No que diz respeito ao período que nos ocupa, a investigação arqueológica no Baixo Guadiana esteve durante vários anos polarizada nos trabalhos desenvolvidos em Castro Marim (a Sul) e Mértola (a Norte), ambos na margem esquerda contando-se também projectos empreendidos pelos municípios de Alcoutim e Sanlúcar de Guadiana, localizados, respectivamente, nas margens portuguesa e espanhola (fig. 2).

Com efeito, em Castro Marim, as escavações sistemáticas permitiram não só um conhecimento preciso da sequência de ocupação deste importante centro regional, mas também a identificação de contextos proto-históricos em extensão (Arruda, 2003; 2008; Arruda e Pereira, 2008; Arruda e Freitas, 2008; Arruda et al., 2007; 2017), a definição de repertórios materiais, bem como a caracterização de uma importante dinâmica comercial desenvolvida ao longo do I Milénio a.C. (Arruda, 2001a; 2005). Estes trabalhos foram a antecâmara do estudo da expansão púnica no Algarve (Arruda, 2007; Sousa e Arruda, 2010).

Em Mértola, por seu turno, os primeiros momentos da vida da cidade são conhecidos quer através de achados casuais, alguns dos quais dados a conhecer por Estácio da Veiga (Barros, 2014; Albuquerque e García, 2017b: 16-19), quer através de intervenções arqueológicas no tecido urbano desde finais da década de 70 do século passado (Regoet al., 1996; Barros, 2008; 2010; 2012). Não obstante, com excepção da muralha da Idade do Ferro (Hourcade et al., 2003) e algumas estruturas romano-republicanas descobertas no início do séc. XX na outra margem (Fabião, 1987), a maioria dos vestígios destas primeiras fases apareceram de forma residual em níveis de épocas posteriores (cf. Albuquerque e García, 2017b). O mesmo pode ser dito dos materiais identificados no actual centro urbano de Alcoutim (conservados no núcleo museológico de Arqueologia desta localidade), alguns dos quais remontam aos sécs. VI e IV a.C. (Município de Alcoutim, 2011, p. 40), que se juntam aos contextos funerários identificados em vários pontos do Concelho (cf. Cardoso e Gradim, 2011).

$\mathrm{Na}$ década passada, as intervenções arqueológicas na área de expansão da Biblioteca Municipal de Mértola (Palma, 2009; 2012) e no Castelinho dos Mouros em Alcoutim (Gradim et al., 2014) colmataram algumas lacunas de informação, ao proporcionarem níveis inalterados de finais da Idade do Ferro e dos primeiros séculos de ocupação romana que, por sua vez, complementam e servem de contraponto da sequência obtida em Castro Marim. Na primeira, obteve-se uma potente estratigrafia com quatro grandes fases de ocupação (proto-histórica, romano republicana, medieval islâmica e moderna), das quais se destacam as mais antigas pelo seu estado de preservação, pelos materiais exumados, pela mais que provável associação à primitiva muralha da Idade do Ferro (reconstruída em torno do séc. II a.C.) e pela identificação de um bastião nas imediações de um dos acessos à cidade (Palma, 2009).

No caso do Castelinho dos Mouros, as escavações sistemáticas desenvolvidas entre 2008 e 2013 exumaram uma fortificação romana (castellum) construída junto ao Guadiana e destinada, possivelmente, ao controlo dos recursos agrícolas e do tráfego fluvial. Ainda que a cronologia de ocupação se situe entre finais do séc. Il e finais do séc. I a.C., a abundante presença de materiais residuais de cronología anterior (sobretudo ânforas, cerâmica comum e de mesa), leva-nos a pensar na existência de um estabelecimento comercial anterior de finais da Idade do Ferro que foi destruído aquando da construção do edifício republicano e cujos restos terão sido utilizados para a nivelação.

No que diz respeito à margem direita, contamos unicamente com dados provenientes de prospecções e escavações preventivas ou de urgência publicados, principalmente, no Anuario Arqueológico de Andalucía. Entre estas intervenções, destacam-se as realizadas no Castelo de San Marcos (Sanlúcar de Guadiana), que se centraram no apoio ao restauro da fortaleza medieval 
e moderna (Campos y Linares, 2006; Linares, 2010). Porém, a recente identificação e escavação de uma necrópole fenícia em Ayamonte, datada entre os sécs. VIII e VII a.C., bem como a posterior descoberta de um possível povoado nas suas imediações (Cabaco e García, 2009; García e Marzoli, 2013), constitui um extraordinário estímulo à investigação sobre a ocupação protohistórica do Baixo Guadiana, ao fornecer novos dados sobre o povoamento fenício do estuário, até então conhecido unicamente no sítio de Castro Marim e adquirindo, por conseguinte, uma dimensão comparável a outros rios atlânticos, nomeadamente o Guadalquivir ou o Guadalete.

No que concerne, por seu turno, ao estudo do território, levaram-se a cabo prospecções, umas mais sistemáticas que outras, nos concelhos portugueses de Vila Real de Santo António, Castro Marim, Alcoutim e Mértola (Gozalbes et al., 1996; Freitas e Oliveira, 2007; Calado e Gradim, 2011; Palma, 2012). Do lado espanhol, as únicas iniciativas comparáveis são as prospecções sistemáticas realizadas no litoral e pré-litoral na margem esquerda do Guadiana (Campos et al., 1992; Gómez et al., 1993) e, sobretudo, o mencionado Catálogo de património fronteirizo publicado há mais de duas décadas (Castaño, 1997), onde se apresenta uma síntese de sítios arqueológicos associados à paisagem de fronteira. Apesar deste desequilíbrio no conhecimento entre um sector e outro do Baixo Guadiana, a informação disponível permite avançar com a identificação de alguns padrões de um povoamento que parece concentrar-se em torno do curso do rio, em lugares altos e próximos a enseadas naturais, com controlo visual da envolvente, ou ainda junto aos principais afluentes do Anas. Estes funcionariam como vias de penetração para o interior destes territórios. A identificação de alguns sítios de época romano-republicana interpretados como guarnições militares (p.ex., Luís, 2003), bem como o estudo das vias romanas que acompanhavam o troço do Guadiana, ligando-o ao Algarve e ao Baixo Alentejo (p.ex., Lopes, 2006; cf. Rodrigues, 2004), por um lado, e aos coutos mineiros de Huelva e ao Baixo Guadalquivir, por outro (Bendala,1987; Gómez et al., 1999; cf. Ruiz Acevedo, 1998), permitiram delinear as rotas terrestres e a sua importância na antiguidade. O uso destas rotas, possivelmente aproveitando traçados preexistentes, revela que, mais além das limitações naturais impostas pelo próprio rio, existiam dois eixos de comunicação principais: um seguia o curso do Anas ( $-N$ ), e outro, que unia de forma transversal o Baixo Alentejo e o interior da Andaluzia (E - W).

No entanto, os dados obtidos nas prospecções realizadas no âmbito do projecto ANA-lise/ ANA-lisis contribuíram para matizar e complementar o panorama exposto, fornecendo indicadores de padrões de povoamento e dinâmicas populacionais que se sucedem neste espaço durante o I Milénio a.C. Nesta primeira fase, como se referiu, concentrámos as atenções no troço compreendido entre o Pulo do Lobo (limite da navegação fluvial do Guadiana, a Norte) e a ribeira de Odeleite, no limite Sul do Concelho de Alcoutim (figs. 1 e 2). A revisão de informações sobre sítios já conhecidos, cotejadas com as obtidas no campo assumiu particular relevância, uma vez que permitiu descartar, por um lado, ocorrências patrimoniais menos claras (p.ex., o Castelo de Pomarão, cuja existência não pôde ser verificada) e, por outro, afinar a cronologia em casos em que os indícios são nulos ou pouco conclusivos. De qualquer modo, devemos reconhecer que os materiais proporcionados por estes sítios são escassos, o que dificulta, amiúde, a definição de uma cronologia de ocupação precisa e, consequentemente, a obtenção de uma perspectiva sincrónica e diacrónica da distribuição do povoamento.

A zona de maior concentração de povoamento situa-se, a julgar pelos dados conhecidos até ao momento, nas margens do Guadiana, aproveitando lugares altos com boa visibilidade, junto a lugares propícios para fundear e navegar para áreas mais interiores (enseadas formadas pelo rio ou desembocaduras dos afluentes). Castro Marim e Mértola parecem ser exemplos nesse sentido, bem como outras ocupações de grandes dimensões que puderam desempenhar funções análogas no início da Idade do Ferro, ainda que parecem ficar subordinadas rapidamente a centros de primeira ordem (fig. 3). 
Figura 3

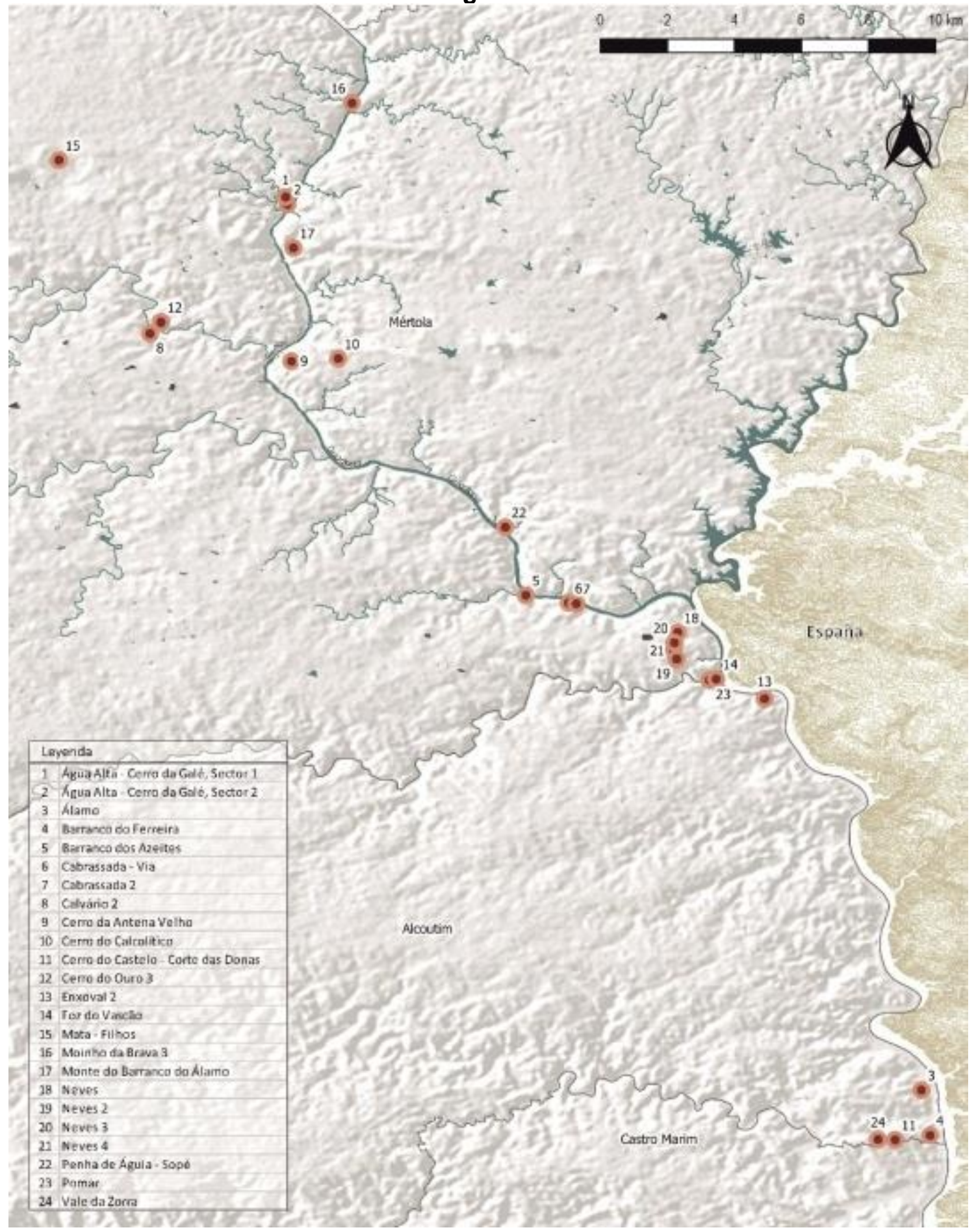

Resultados das prospecções levadas a cabo nos Concelhos de Mértola e Alcoutim (2016 e 2017). Distribuição dos sítios correspondentes ao período em estudo (sécs. VIII a.C. - I d.C.). 
Tal parece ser o caso de Água Alta, localizado a Norte de Mértola junto a um meandro do Guadiana e com um extraordinário domínio visual do seu curso, tanto a montante como a jusante. Uma primeira observação preliminar permite afirmar que os materiais identificados à superfície apontam para, pelo menos, duas fases de ocupação: a primeira, entre finais da Idade do Bronze e inícios da Idade do Ferro, pode corresponder a um povoado ribeirinho destinado à transformação e comercialização da produção metalúrgica, como sugerem os vestígios de escória encontrados em vários pontos do cerro. Na segunda, é provável que o sítio estivesse destinado ao controlo da navegação fluvial e, inclusive, à protecção do acesso fluvial ao oppidum de Mértola, posto que ocupa uma evidente posição estratégica da sua retaguarda (García Fernández et al., 2017b, p. 165). Esta possível função de vigilância, por sua vez associada ao tráfego e armazenamento de mercadorias, é atribuída a outras ocupações de menor dimensão que acompanham o curso do rio desde os últimos troços navegáveis, a montante de Mértola, até à foz.

A alguns sítios já conhecidos, nomeadamente Alcoutim ou Cerro da Velha e Moinho de Carvão, já no interior da Ribeira da Foupana (Freitas e Oliveira, 2007, p. 412), juntam-se outros, nomeadamente Pomar (fig.s 3 e 4), junto à desembocadura do Vascão, Álamo, onde se identificaram fragmentos cerâmicos da II Idade do Ferro nas imediações da villa alto-imperial descoberta por Estácio da Veiga (Cardoso e Gradim, 2011, p. 200 - 202), Barranco do Ferreira, datáveis entre os séculos III e I a.C. e, de acordo com estudos recentes, Castelinho dos Mouros, onde se registaram, como se disse, materiais claramente pré-romanos.

Observa-se também uma concentração de ocupações em zonas mineiras e, sobretudo, nas vias que ligam estas últimas ao curso do Guadiana, tanto fluviais (Ribeira de Oeiras, Chança, Odeleite, etc.) como terrestres (fig. 3). Ambas dão acesso a coutos mineiros mais distantes, nomeadamente Neves - Corvo (no interior alentejano) e Tharsis (província de Huelva), cuja produção pode ter sido escoada através do Guadiana (Maia, 2008; Gómez et al., 1999). Nesse sentido, tivemos oportunidade de examinar a via natural que liga Mértola às Minas de São Domingos, onde se encontram sítios como Texugueira e Cerro do Calcolítico. No primeiro, identificaram-se materiais sidéricos numa escavação realizada em 1997 (Palma, 2012: 105). O segundo foi localizado em 1984 e prospectado em 1991, definindo-se duas fases, uma do Calcolítico e outra de finais da Idade do Ferro (Pérez e Rego, 1994). A aparição de um bordo de ânfora e de cerâmicas de tradição turdetana corrobora a existência desta última fase, que possivelmente coincide com o início da presença romana.

Por seu turno, a Oeste de Mértola, conhecem-se Calvário 2 e Cerro do Ouro, ambos junto à margem direita da Ribeira de Oeiras (figs. 2 e 3) e numa área relativamente afastada do Guadiana, possivelmente destinados à exploração mineira (a julgar pelos vestígios de extracções modernas e restos de mineral de ferro). Os dados conhecidos não são suficientes para definir a função ou a cronologia, situada genericamente entre finais da Idade do Ferro (sécs. IV - III a.C.) e o período romano (Palma, 2012, p. 81 e 238).

Ainda no âmbito da exploração mineira, os primeiros estabelecimentos romanos nesta área surgem associados a importantes vias de comunicação. Interpretaram-se como guarnições militares pelo seu tamanho, implantação estratégica e aparição recorrente de materiais itálicos, especialmente ânforas vinárias (Luís, 2003, p. 378 - 380). Destinar-se-iam ao controlo das principais vias de abastecimento ao exército, mas também do escoamento dos metais extraídos na região. Destacam-se, neste contexto, três sítios: Cerro da Antena, implantado no topo de uma colina localizada a Este de Mértola, que domina a partir da margem esquerda o curso do Guadiana e a referida via que conduzia a São Domingos; Mata - Filhos, um estabelecimento fortificado instalado sobre uma colina de pendente suave nas proximidades da via Myrtilis - Pax Ivlia e de uma zona de alto potencial agrícola (fig. 5). Por último, o castellum de Manuel Galo, conhecido há várias décadas e destinado, como os anteriores, à vigilância de territórios de alto interesse económico (Palma, 2012, p.89). 
A escassez de sítios proto-históricos associados a estas zonas de alto potencial agrícola pode ser explicada de dois modos: ou o povoamento estava concentrado em torno dos grandes núcleos, do rio e das zonas mineiras, ou estamos perante uma lacuna de investigação que ainda não foi colmatada. A identificação de povoados, necrópoles e lugares de culto noutros municípios alentejanos (Castro Verde, Ourique e Beja: Arruda, 2001b; 2008), do mesmo modo que a presença de espigas nas emissões de Myrtilis e Sirpens (Serpa), pode conduzir a optar pela segunda hipótese. Este elemento iconográfico remete, evidentemente, para outras vocações económicas mais além da exploração mineira (cf. Albuquerque e García, 2017b, p. 11-14, com bibliografia) que ainda não foram detectadas no registo arqueológico.

Perante este panorama, torna-se necessário intensificar o estudo das freguesias interiores dos concelhos de Mértola e Alcoutim, nomeadamente Alcaria Ruiva e Martinlongo, bem como da parte oriental da comarca espanhola de Andévalo, com o propósito de identificar um tecido agrícola estável e adequado às necessidades desta estrutura populacional. Porém, não é incoerente considerar a existência de diferenças nos padrões de fixação, ou mesmo de pautas culturais, bem como o próprio factor tempo. Neste sentido, aprecia-se uma evolução ao longo do I Milénio a.C., tanto à escala regional como no que diz respeito à Bacia baixa do Guadiana, onde à aparente continuidade dos eixos territoriais estruturantes se juntam novas tipologias de habitats e modelos de ocupação, que por sua vez representam a antecâmara da romanização desta região, numa dinâmica que relaciona, por um lado, o mar e o interior e, por outro, as províncias romanas da Bética e da Lusitânia.

\section{Figura 4}

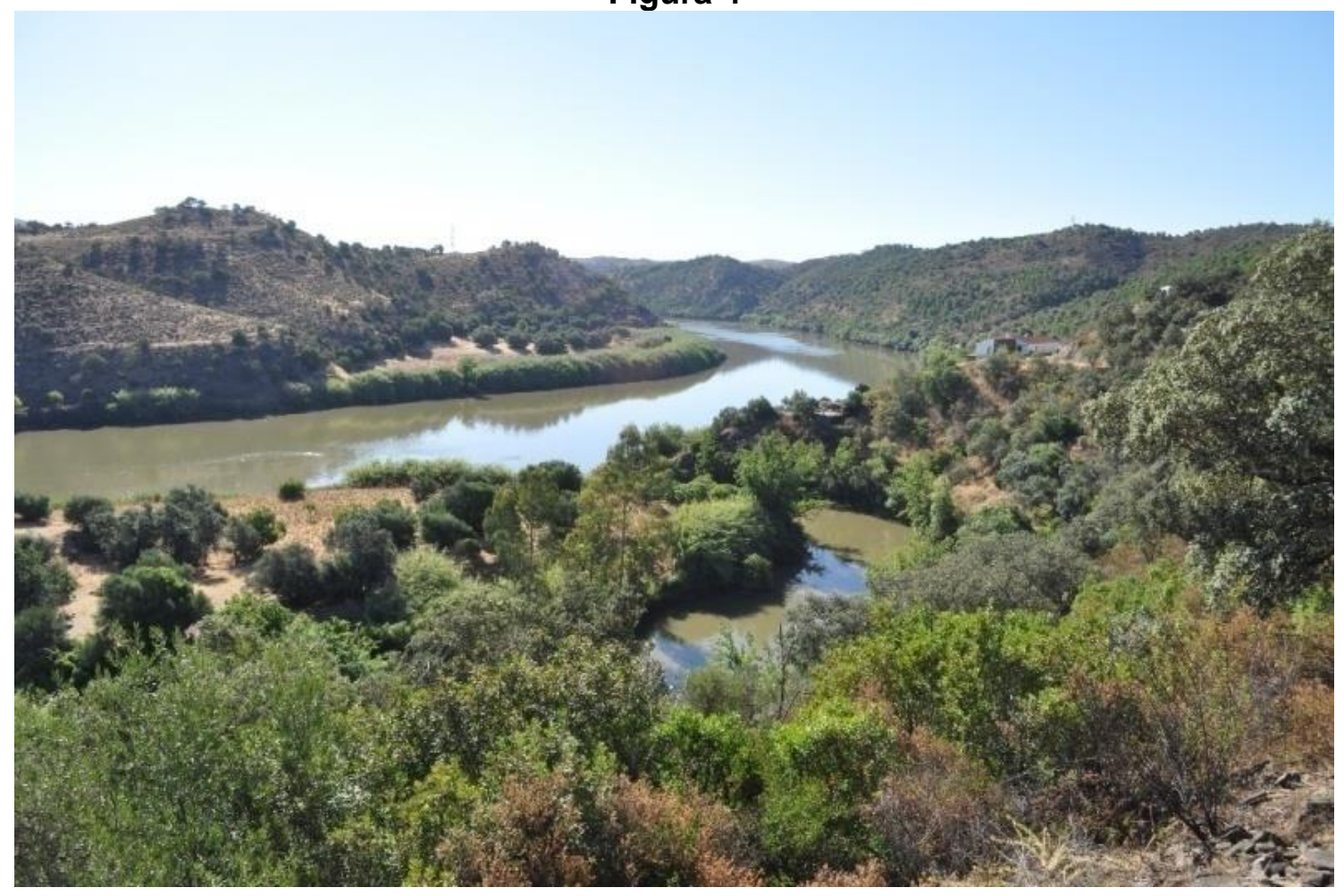

Sítio de Pomar (à direita), junto à desembocadura da Ribeira do Vascão no Guadiana. Ao fundo, a margem espanhola, Fotografia: FJGF. 


\section{Em jeito de síntese: estruturas e conjunturas de um proceso de longue durée}

Tivemos oportunidade de assinalar que um dos traços que caracterizam o povoamento do Baixo Guadiana é a sua consistência e durabilidade, mantendo-se uma estrutura básica possivelmente polarizada em dois grandes núcleos, Castro Marim e Mértola, durante grande parte do I Milénio a.C. Aparentemente, o interior não foi afectado pelo processo de abandono ou retrocesso registado na antiga Baesuris entre os sécs. III e I a.C. e noutros pontos do Algarve (Sousa, 2017, p.197). Pelo contrário, a multiplicação de pequenas ocupações (anteriormente citadas) revela, precisamente, o fenómeno inverso. Chama também a atenção a afinidade cultural, revelada pelos repertórios materiais, entre os vários sítios, especialmente entre os dois grandes polos. Esta constatação é ainda mais evidente se se comparam estes dados com os que foram obtidos no interior do Alentejo ou nos territórios a montante do Pulo do Lobo. Com efeito, as diferenças apreciadas ao nível do modelo de ocupação e da cultura material entre as comunidades do Baixo Guadiana e as do resto do Alentejo e do Norte da província de Huelva, à medida que a Idade do Ferro avança, é um dos traços que definem este território.

Podemos, portanto, perguntar: é pertinente definir este território como fronteira? Como vimos anteriormente, a polissemia do conceito obriga a considerar, antes de mais, o tipo de fronteira que se pretende analisar, bem como o momento a que nos referimos. Permita-se-nos justificar esta afirmação.

Parece evidente que o início da presença fenícia em torno do séc. VIII a.C. (em cronologia tradicional) dotou o Sudoeste peninsular de uma aparente homogeneidade cultural que não anulou as particularidades regionais resultantes do contacto com o movimento colonizador. Há que considerar, por outro lado, a mais que provável diversidade do substrato étnico preexistente (Arruda, 2010). Após a crise do séc. VI a.C., que afectou tanto as áreas costeiras como interiores da Andaluzia, essas particularidades começaram a acentuar-se. Assim, estes processos- também regionais -deram origem a novas realidades sociais, políticas e culturais, que não foram, logicamente, alheias à adaptação a novas conjunturas económicas.

A partir do séc. $V$ a.C., assiste-se a uma diferenciação entre a região turdetana (que chega às margens do Guadiana), o Baixo Alentejo (Castro Verde, Ourique e Beja) e o Alentejo Central, que mantiveram durante mais de um século os traços de matriz oriental da etapa prévia, especialmente as duas últimas regiões, mais vinculadas ao Médio Guadiana que ao seu estuário. Assim, o chamado "pós-orientalizante parece tratar-se de um epifenómeno, que não tem paralelo no litoral, nem na forma nem no conteúdo, e que com esse litoral não parece estar directamente relacionado, o que não significa que não houvesse, entre as duas áreas, através ou não da via fluvial, qualquer contacto" (Arruda, 2008, p. 321). Neste sentido, também na opinião da autora, a Sierra Morena foi mais determinante como barreira física para estas populações do que o próprio curso do Guadiana, que continuou a ligar, mais do que a separar, as gentes as duas margens.

A chamada "crise de 400", que põe termo ao fenómeno "pós-orientalizante" do Guadiana Médio, e a instalação de populações de matriz céltica no Alentejo e Extremadura espanhola, é, nesse sentido, a antecâmara da formação de novas realidades geoetnográficas (p.ex., a Betúria céltica) que acentuaram essas diferenças (Berrocal, 1993). Ainda que possam apreciar-se algumas perdurações na zona de Ourique, especialmente no que diz respeito ao uso dos espaços de culto (Gomes, 2012, p. 108ss), o desaparecimento dos pequenos estabelecimentos rurais e das necrópoles em toda esta região, alcançando praticamente a margem direita do Guadiana, gera um contraste do qual se podem tirar algumas ilações para a interpretação da construção de fronteiras. Por outro lado, regista-se a intensificação da presença púnica na costa algarvia a partir do séc. IV a.C. (cf. Sousa e Arruda, 2010), que acaba por ser influente nas terras interiores, tanto 
comercial como culturalmente. O santuário de Garvão e a própria Myrtilis podem ser, nesse sentido, exemplos eloquentes da formação de espaços de encontro privilegiados ou, por outras palavras, multiculturais (Albuquerque e García, 2017b).

A grande diversidade e forte interacção fez, portanto, do Guadiana um espaço de transição entre áreas culturais diferentes, mas com interesses económicos comuns, e não tanto um limite físico intransponível. Assim, a imagem de uma fronteira definida e estável do ponto de vista territorial não parece aplicável à realidade que acabamos de descrever. É, por isso, mais provável que estas diferenças fossem mais visíveis no plano pessoal, dando lugar ao que se definiu, noutras ocasiões, como fronteiras simbólicas, internas ou sociais, e que se definem, precisamente, pela sua construção dinâmica através das relações que se estabelecem entre indivíduos e grupos (Rizo e Romeo, 2006; Pech et al., 2009; cf. supra). Nesta dimensão das relações interpessoais,as fronteiras projectam-se nos objectos, nos comportamentos, nas práticas quotidianas, indumentária, na linguagem e até mesmo no próprio corpo, contribuindo para a categorização de pessoas e para a formação e consolidação de relações de pertença e exclusão. Estas fronteiras são, necessariamente, mais difusas e flexíveis, uma vez que se desenvolvem no seio de comunidades heterogéneas do ponto de vista cultural e socialmente complexas, como parece ser o caso dos grupos que habitaram as margens do Baixo Guadiana. Tal não exclui a existência de fronteiras políticas entre os principais centros de poder que, como se sabe, são, arqueologicamente, pouco visíveis.

Com a chegada de Roma, estas fronteiras culturais diluem-se paulatinamente à medida que as populações do Sudoeste peninsular se integram no modus vivendi romano. Este processo culmina com a reforma de Augusto e a definitiva provincialização deste território em 27 a.C. É, nesse sentido, interessante constatar que Myrtilis é atribuída pelos geógrafos antigos aos Lusitanos (Plin., Nat. 3.116 - 117), aos Turdetanos (Ptol., Geo. 2.5.5) ou aos Cuneus (Mela 3.7), um dos povos (Cynetes, Conii) que as fontes greco-latinas situam, normalmente, nos confins atlânticos da Ibéria (Pérez Vilatela, 1995). Isto não significa que não se tenham mantido algumas particularidades, especialmente numa região etnicamente dinâmica e resistente durante os primeiros séculos de domínio romano (García Moreno, 1998). Note-se ainda a já citada presença de recintos fortificados, que pode ser uma evidência desta conjuntura de conquista, bem como a própria romanização precoce de Mértola (cf. Fabião, 1987).

Como dizíamos, a provincialização de Augusto estabelece a primeira fronteira administrativa conhecida historicamente nesta região, dando início a uma nova estrutura política, na qual o Guadiana passa a funcionar, durante vários séculos, como o limite entre a Bética e a Lusitânia (Pérez Vilatela, 1990; Albuquerque et al. 2018). Não obstante, como também tivemos oportunidade de referir, o papel do rio como fronteira natural foi sobrevalorizado pela investigação a partir de uma leitura linear da informação fornecida pelas fontes clássicas. Nesse sentido, algumas vozes críticas matizaram, com argumenos sólidos, a delimitação exacta das duas províncias mediante o estudo combinado das fontes literárias, epigráficas e itinerárias em relação, sobre tudo, com os territórios das comunidades fronteiriças (Alves e Ramírez, 2016; España, 2017, p. 177ss). Para o último autor, "hay que entender el Anas como una sucesión de espacios que van ejerciendo de límite interprovincial a lo largo de su recorrido, sin prejuicio de que el territorium de una ciudad se extienda a ambas márgenes. Hay que considerar Anas como valle y no como cauce" (España, 2017, p. 282). Isto explica as mutações que a fronteira sofre ao longo da Antiguidade Tardia, durante a qual as dioceses episcopais implementam uma nova demarcação territorial que convive com a provincial (Sánchez e Salas, 2016, p. 205ss.), e que de algum modo determinarão 
as fronteiras das primeiras kuras islâmicas medievais. Mas isto é, logicamente, farinha de outro saco.

Figura 5

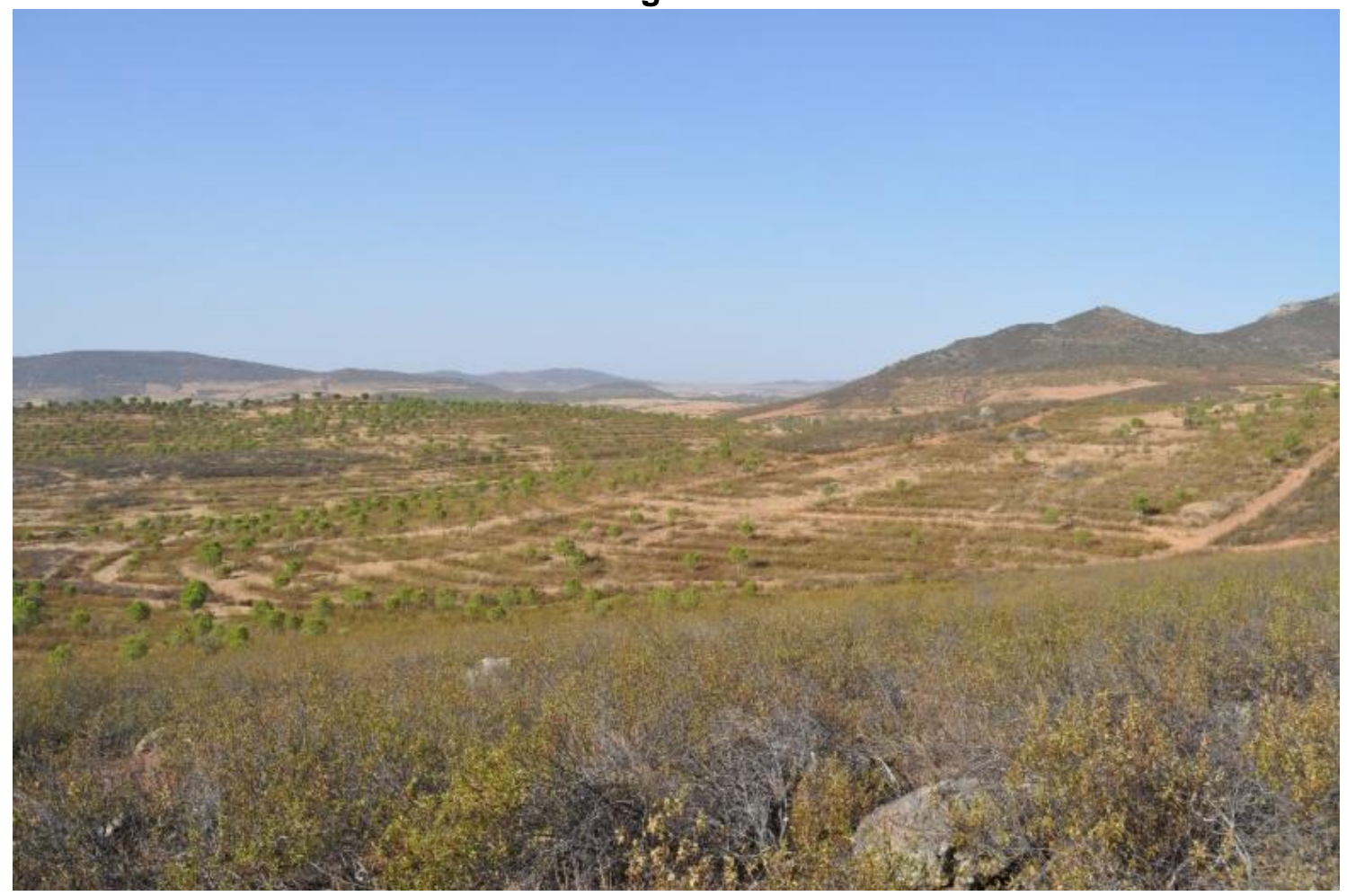

Sítio de Mata - Filhos, vista para Sul com a via que una Myrtilis (Mértola) e Pax Ivlia (Beja) ao fundo. Fotografia: FJGF.

\section{Considerações finais sobre um passado (e futuro) partilhado}

É comum pensar na imagem de Portugal olhando na direcção do Atlântico e de Espanha na direcção dos países do Norte, ambos com costas voltadas para os espaços onde os seus poderes se encontram. O papel da educação foi, nesse sentido, determinante para a transmissão de valores morais sobre as respectivas nações e, sobretudo, sobre a imagem do vizinho (cf. Lois e Carballo, 2015). Esta trajectória, rastreável nos programas escolares e até mesmo no próprio imaginário popular, resulta, p.ex., em expressões como "de Espanha nem bom vento nem bom casamento", alusivas à perda de independência com políticas matrimoniais.

Não é, nem poderia ser, esta a ocasião para apresentar uma reflexão sobre estes aspectos na história recente dos dois países, mas não deixa de ser relevante o facto de esta imagem ter, de facto, condicionado o modo como os territórios fronteiriços foram caracterizados e analisados por intelectuais de vários campos do saber ou, melhor dito, ignorados e esquecidos. Como se disse, o livro de Pintado e Barrenechea (1972) é uma referência incontornável, pois apresentou uma imagem dos territórios raianos que passou, poucos anos depois, a fazer (finalmente) parte das reflexões científicas, anunciando a necessidade de intervenções de fundo nestes espaços. Por outro lado, é evidente que a tal imagem transmitida no ensino estava longe de ser a da cooperação e da interacção, o que certamente levou a que o Guadiana ocupasse, na maioria (ou mesmo na totalidade) dos casos, uma posição periférica na investigação histórica e geográfica. 
A análise do povoamento do rio é, portanto, uma oportunidade para contrariar esta tendência e ampliar o conhecimento sobre a história das relações das sociedades com o rio, bem como para consolidar metodologias para o estudo das fronteiras territoriais e simbólicas. Como tivemos oportunidade de ver, o estado actual da gestão dos territórios fronteiriços constitui um desafio que deve resultar em propostas de valorização patrimonial que devem ser sustentáveis a vários níveis (social, económico, cultural e ambiental), no sentido de criar novos focos de interesse nestes espaços. Nas linhas precedentes procurámos valorizar este sector da fronteira hispano-lusa em momentos nos quais o Guadiana não funcionou, efectivamente, como um elemento de separação política ou administrativa, mas sim como um espaço de transição entre comunidades, gerando, como na actualidade, situações de encontro, convivência, cumplicidade e mestiçagem, que se evadem das esferas de domínio, projectando-se no quotidiano através dos difusos e dinâmicos limites interpessoais. Consideramos que o Guadiana "antes da fronteira" constitui um argumento insuficientemente valorizado até ao momento, mas pode contribuir para a consolidação de relações de pertença e identidade das populações ribeirinhas, dando especial destaque à ligação secular entre as duas margens antes da formação e delimitação dos estados modernos. Neste sentido, cremos que o património arqueológico constitui um recurso fundamental para dar visibilidade a este passado partilhado, assumindo que faz parte de um contexto territorial amplo e com uma inquestionável riqueza histórica, cujo conhecimento e difusão permite criar laços com outros valores patrimoniais, medio-ambientais e etnográficos, mas, sobretudo, eliminar o efeito da fronteira no discurso educativo dos dois países.

\section{Referências:}

AAVV. Actas de las I Jornadas transfronterizas sobre la Contienda Hispano-portuguesa, 2 al 4 de junio de 1995.Aroche: Escuela Taller Contienda, 1996.

ALBUQUERQUE, P. O Guadiana como fronteira? Notas para um projecto de investigação. Ophiussa, Lisboa, n. 1, p. 35-44, 2017.

ALBUQUERQUE, P.; GARCÍA FERNÁNDEZ, F.J. Sobre o conceito de fronteira: o Guadiana numa perspectiva arqueológica. IN: CELESTINO PÉREZ, S.; RODRÍGUEZ GONZÁLEZ E. (Eds.),Territorios comparados: los valles del Guadalquivir, el Guadiana y el Tajo en época tartésica.Mérida: CSIC, 2017a. p. 175-182. Anejos de Archivo Español de Arqueología,LXXX.

ALBUQUERQUE, P.; GARCÍA FERNÁNDEZ, F.J.Mértola entre el Bronce Final y el inicio de la presencia romana: problemas y perspectivas de investigación. Habis, Sevilla, n. 48, p. 7-30, 2017b.

ALBUQUERQUE, P.; PEREIRA, C.; TEIXEIRA, S., Elementos e perspectivas para el estudio del Anas como frontera en la Antigüedad: Fuentes clásicas, registro arqueológico y epigrafía. Revista Onoba, Huelva, n. 6, p. 3-19, 2018.

ALVES DA FONSECA, N.; VERDUGO SANTO, J.; PLATA GARCÍA, F. La cooperación transfronteriza y el Patrimonio histórico: Protección y Difusión. IN: Actas de las I Jornadas transfronterizas sobre la Contienda Hispano - portuguesa. Aroche: Escuela Taller La Contienda, 1996. Vol. 1, p. 333-354.

ALVES DÍAS, M.; RAMÍREZ SÁDABA, J.L. En torno al límite entre Lusitania y Bética. Estado de la cuestión. IN: CARBONELL MANILS, J.; GIMENO PASCUAL, h. (Eds.). A Baete ad fluvium Anam: Cultura epigráfica en la Bética Occidental y territorios fronterizos. Homenaje al profesor José Luis Moralejo Álvarez. Alcalá de Henares; Universidad de Alcalá, 2016. p. 23-40. AMANTE, M. DE F. Cultura e cooperação: desafios e entraves à relação ibérica no contexto europeu. População e Sociedade, Porto, n. 17, p. 155-178, 2009.

ARRUDA, A.M. Importações púnicas no Algarve: cronologia e significado. IN: TAVARES, A.A. et al. (Eds.). Os púnicos no Extremo Occidente. Lisboa: Universidade Nova de Lisboa, 2001a. p. 69-98. 
ARRUDA, A.M. A Idade do Ferro pós-orientalizanteno Baixo Alentejo. Revista Portuguesa de Arqueologia, Lisboa, v. 4, n. 2, p. 207-291. 2001.

ARRUDA, A.M. Escavações arqueológicas no Castelo de Castro Marim - balanço e perspectivas. IN: Actas do Io Encontro de Arqueologia do Algarve. Silves: Museu Municipal de Arqueologia de Silves, 2003. p. 69-88. Xelb, 4.

ARRUDA, A.M. As cerâmicas de importação do Castelo de Castro Marim: no âmbito do comércio ocidental dos séculos V a III a.C. IN: Actas del IV Congreso Internacional de Estudios Fenicios y Púnicos. Cádiz: Universidad de Cádiz, 2000. p. 727-735.

ARRUDA, A.M. A Idade do Ferro do sul de Portugal. Estado da investigação. Madrider Mitteilungen, Mainz, n. 48, p. 114-139, 2007.

ARRUDA, A.M. O Baixo Guadiana durante os séculos VI e V a.n.e. IN: JIMÉNEZ ÁVILA, J. (Ed.). Sidereum Ana I: El río Guadiana en época post-orientalizante. Mérida: CSIC, 2008. p. 307-325. Anejos de Archivo Español de Arqueología, XLVI.

ARRUDA, A.M. Fenícios no território actualmente português: e nada ficou como antes. BANDERA ROMERO, Ma. .L DE LA; FERRER ALBELDA, E. (Coord.). El Carambolo: cincuenta años de un tesoro. Sevilla: Universidad de Sevilla, 2010. p. 439-452.

ARRUDA, A.M.; FREITAS, V.T. O Castelo de Castro Marim durante os séculos VI e V a.n.e. IN: JIMÉNEZ ÁVILA, J. (Ed.). Sidereum Ana I: El río Guadiana en época post-orientalizante. Mérida: CSIC, 2008. p. 429-446. Anejos de Archivo Español de Arqueología, XLVI.

ARRUDA, A.M.; PEREIRA, C. As ocupações antigas e modernas do Forte de São Sebastião, Castro Marim. Actas do 5o Encontro de Arqueologia do Algarve. Silves: Museu Municipal de Arqueologia de Silves, 2008. Vol. 1, p. 365-395. Xelb, 8.

ARRUDA, A.M.; FREITAS, V.T.; OLIVEIRA, C. Os fenícios e a urbanização no Extremo Ocidente: o caso de Castro Marim. IN: LÓPEZ CASTRO, J.L. (Ed.). Las ciudades fenicio-púnicas en el Mediterráneo Occidental. Almería: Universidad de Almería,2007. p. 459-482.

ARRUDA, A.M.; OLIVEIRA, C.F.; FREITAS, V.T. Castro Marim entre indígenas, fenícios e tartéssicos". IN: JIMÉNEZ ÁVILA, J. (Ed.). Sidereum Ana III: El río Guadiana y Tartessos, Mérida, CSIC, 2017. p. 443-466.

BARRIENTOS ALFAGEME, G. La ampliación de la CEE y el diseño del espacio ibérico. Revista de Estudios Regionales, Málaga, n. 18, p. 125-137, 1987.

BARROS, P. Mértola durante os séculos VI e V a.C. IN: JIMÉNEZ ÁVILA, J. (Ed.). Sidereum Ana I: El río Guadiana en época post-orientalizante. Mérida: CSIC, 2008. p. 399-414. Anejos de Archivo Español de Arqueología, XLVI.

BARROS, P. Mértola entre os séculos VI e III a.C. Maikake, Málaga, n. 32 (1), 2010. p. 417-436. BARROS, P. O Bronze Final na região de Mértola. IN: JIMÉNEZ ÁVILA, J. (Ed.). Sidereum Ana II: El río Guadiana en el Bronce Final. Mérida: CSIC, 2012. p. 215-227. Anejos de Archivo Español de Arqueología, LXII.

BARROS, P. Mértola, plataforma comercial durante a Idade do Ferro. A colecção de Estácio da Veiga. IN: ARRUDA, A. (Ed.). Fenícios e Púnicos, por terra e por mar. Lisboa: UNIARQ, 2014. Vol. 2, p. 688-697.

BEIRÃO, C. de M.; SILVA, C.T. da: SOARES, J.: GOMES, M.V.; GOMES, R.V. Depósito votivo da II Idade do Ferro de Garvão. Notícia da primeira campanha de escavações, O Arqueólogo Português, Lisboa, série IV, n. 3, p. 45-135, 1985.

BENDALA GALÁN, M. Ab ostio fluminis Anae... Cuadernos de Prehistoria y Arqueología de la Universidad Autónoma de Madrid, Madrid, p. 129-139, 1987.

BERROCAL RANGEL, L. Los pueblos célticos del suroeste de la Península lbérica. Madrid: Universidad Complutense de Madrid, 1993.

CABACO ENCINAS, B.; GARCÍA TEYSSANDIER, E. Hallazgos fenicios en Ayamonte (Huelva): la necrópolis de la Hoya de los Rastros y materiales del hábitat en la Mesa del Tejar. IN: PÉREZ 
MACÍAS, J.A.; ROMERO BOMBA, E. (Coord.). IV Encuentro de Arqueología del Suroeste. Huelva: Universidad de Huelva, 2009.p. 730-745.

CABERO, V.; CAMPESINO, A.J.; LÓPEZ, I. Knowledge of border areas: the contribution of Spanish Geographers. Boletín de la Asociación de Geógrafos Españoles, Madrid, n. 21-22, p. 83-98, 1995-1996.

CABO ALONSO, A. Presentación. IN: Actas del I Coloquio Ibérico de Geografía. Salamanca: Ediciones de la Universidad de Salamanca, 1981. p. 9-15.

CAFLISCH, L. Essai d'une typologie des frontières. Relations Internationales, Paris, n. 63, p. 265-293, 1990.

CAMPESINO FERNÁNDEZ, A.J. La frontera como factor geográfico: situación actual de la investigación peninsular. IN: Primeras Jornadas Ibéricas de Investigadores de Ciencias Humanas y Sociales. Olivenza, 18-19-20 octubre, 1985: Acta, ponencias y comunicaciones. Salamanca: Diputación Provincial de Badajoz, 1987. p. 207-224.

CAMPESINO FERNÁNDEZ, A.J. Territorio y paisajes patrimoniales de la raya ibérica. El espacio geográfico de la EUROACE. IN: Jornadas internacionales sobre la frontera hispanoportuguesa y sus fortificaciones: Badajoz, 8, 9 y 10 de noviembre de 2012.Badajoz: Ayuntamiento de Badajoz, 2014. p. 51-74.

CAMPESINO FERNÁNDEZ, A.J.; JURADO ALMONTE, J.M. (Dirs.). Turismo de Frontera (III) Productos turísticos de la Raya ibérica. Huelva:Universidad de Huelva, 2014.

CAMPOS CARRASCO, J.M.; BORJA BARRERA, F.; CASTIÑEIRA SÁNCHEZ, J.; GÓMEZ TOSCANO, F.; GARCÍA RINCÓN, J.Mª . Prospección arqueológica superficial en el litoral y prelitoral entre el Guadiana y el Guadalquivir. Anuario Arqueológico de Andalucía 1990, vol. II, p. 76-83, 1992.

CAMPOS JARA, P.; LINARES CATELA, J.A. Intervención arqueológica de apoyo a la restauración del Castillo de Sanlúcar del Guadiana (Huelva). 1aㅡ fase. Anuario Arqueológico de Andalucía, Sevilla, 2003, vol.II, p. 254-265, 2006.

CARDOSO, J.L.; GRADIM, A. Dez anos de trabalhos arqueológicos em Alcoutim. Do Neolítico ao romano. Alcoutim: Câmara Municipal de Alcoutim, 2011.

CARRASCO GONZÁLEZ, M.; VIUDAS CAMARASA, A. (Eds.). Congreso Internacional LusoEspanhol de Lengua y Cultura en la Frontera,1 a 3 de Dezembro de 1994. Cáceres: Universidad de Extremadura, 1996. 2 vols.

CARRIAZO RUBIO, J.L. La frontera andaluza del Guadiana durante la Baja Edad Media. IN: VI Jornadas de Historia de Ayamonte. Ayamonte: Patronato Municipal de Cultura de Ayamonte, 2002. p. 85-100.

CASTAÑO MADROÑAL, A.; GÓMEZ TOSCANO, F.; HERNÁNDEZ LEÓN, E.; SÁNCES DE LAS ERAS, C.; SÁNCHEZ ROMERO, J. Catálogo de Bienes de Interés del Entorno Fronterizo del Bajo Guadiana: Ayamonte, Villablanca, San Silvestre de Guzmán, Sanlúcar de Guadiana, EI Granado. Huelva: Consejería de Cultura, Junta de Andalucía, 1997.

CASTELO BRANCO, M.S. Duarte d'Armas: Livro das Fortalezas. Lisboa: Arquivo Nacional da Torre do Tombo e Edições INAPA,1996.

CASTRO, L.D. (Coord.). A Cooperação transfronteiriça entre Portugal e Espanha. Vigo: EixoAtlântico do Nordeste peninsular, 2008.

CASTRO MARTÍNEZ, P.V.; GONZÁLEZ MARCÉN, P. El concepto de frontera: implicaciones teóricas de la noción de territorio político. Arqueología Espacial, Teruel, n. 13, p. 7-18, 1989.

CAVACO, C. Nota de apresentação. IN: CAVACO, C. (Coord.). As regiões de fronteira: Inovação e desenvolvimento na perspectiva do Mercado Único Europeu. Lisboa: CEG, 1995a. p. 7-8.

CAVACO, C. A fronteira política: da divisão à integração territorial. IN: CAVACO, C. (Coord.). As regiões de fronteira: Inovação e desenvolvimento na perspectiva do Mercado Único Europeu. Lisboa: CEG, 1995b. p. 9-17. 
CAVACO, C. Um olhar sobre a fronteira Portugal - Espanha. IN: CAVACO, C. (Coord.). As regiões de fronteira: Inovação e desenvolvimento na perspectiva do Mercado Único Europeu. Lisboa: CEG, 1995c. p. 19-34.

CAVACO, C. Planificação transfronteiriça e desenvolvimento local e regional.IN: CAMPESINO FERNÁNDEZ, J.; VELASCO BERNARDO, C. (Eds.). Portugal - España: Ordenación territorial del suroeste comunitario. Acta, ponencias y comunicaciones. VII Congreso lbérico de Geografía. Cáceres: Universidad de Extremadura, 1996. p. 421-434.

CAVACO, C. Fronteira Portugal - Espanha e individualidade territorial. Finisterra, Lisboa, v. 32, n. 63, p. 159-166, 1997.

CLAVAL, P. L'étude des frontières et la géographie politique. Cahiers de Géographie du Québec, Laval, v.18, n. 43, p. 7-22, 1974.

COSME, J. A construção da fronteira na margem esquerda do Guadiana (Sécs. XIII - XVII). IN: Jornadas internacionales sobre la frontera hispano-portuguesa y sus fortificaciones: Badajoz, 8, 9 y 10 de noviembre de 2012.Badajoz: Ayuntamiento de Badajoz, 2014. p. 145-153.

DOCTOR CABRERA, A. Organización jerárquica de la red de asentamientos de un espacio transfronterizo: Alentejo-Algarve-Huelva. IN: MÁRQUEZ DOMÍNGUEZ, J.A.; GORDO MÁRQUEZ, M. (Eds.). Fronteras en movimento. Huelva: Universidad de Huelva, 2014. p. 109-120.

ESPAÑA CHAMORRO, S. Límites y territorios de la Bética romana. 2017. Tese doctoral, Facultad de Geografía e Historia, Universidad Complutense de Madrid, Madrid, 2017.

FABIÃO, C. Ânforas romanas republicanas de um depósito de Mértola no Museu Nacional de Arqueologia e Etnologia. O Arqueólogo Português, Lisboa, Série IV, n. 5, p. 125-148, 1987.

FARIA, A.M. Novas notas historiográficas sobre Augusta Emerita e outras cidades hispanoromanas. Revista Portuguesa de Arqueologia, Lisboa, 9 (2), p. 211-237, 2006.

FELICIDADES GARCÍA, J.; GARCÍA DELGADO, F.J. Articulación urbana en el suroeste ibérico. IN: MÁRQUEZ DOMÍNGUEZ, J.A.; GORDO MÁRQUEZ, M. (Eds.). Fronteras en movimento. Huelva: Universidad de Huelva, 2014. p. 121-138.

FELICIDADES GARCÍA, J. Hacia una cartografía transfronteriza hispano-portuguesa: avances y reflexiones desde la escala local. IN: MÁRQUEZ DOMÍNGUEZ, J.A.; JURADO ALMONTE, J.M.; PAZOS GARCÍA, F.J. (Eds.). Desarrollo local en territorios de fronteras. Huelva: Universidad de Huelva, 2016. Não paginado.

FERREIRA, M.J. As regiões fronteiriças portuguesas: potencialidades de desenvolvimento no actual contexto de internacionalização. Revista da Faculdade de Ciências Sociais e Humanas, Lisboa, n. 11, p. 337-353, 1998.

FREIRE, D.; ROVISCO, E.; FONSECA, I. (Coords.). Contrabando na fronteira luso-espanhola: práticas, memórias e patrimónios. Lisboa:Nelson de Matos, 2009.

FREITAS, V.T.; OLIVEIRA, C.P. A Idade do Ferro no Baixo Guadiana. IN:Actas del IV Congresso de Arqueologia Peninsular. Faro: Universidade do Algarve, 2007. p. 409- 418. Promontoria Monográfica, 9.

GARCIA, J.C. La frontera luso - española y los estudios de geografía histórica. IN: LÓPEZ TRIGAL, L.; GONZÁLEZ, R.L.; GUICHARD, F. (Eds.). La articulación territorial de la raya hispanoportuguesa. Zamora: Fundación Rei Afonso Henriques, 1997. p. 25-29.

GARCÍA FERNÁNDEZ, F.J. Tartesios, Túrdulos, Turdetanos. Realidad y ficción de la homogeneidad étnica de la Bética Romana. SANTOS YANGUAS, J.; CRUZ ANDREOTTI, G. (Eds.). Romanización, fronteras y etnias en la Roma Antigua: el caso hispano. Vitoria: Universidad de Vitoria, 2012, p. 691-734. Revisiones de Historia Antigua, VII.

GARCÍA FERNÁNDEZ, F.J.; DEL ESPINO HIDALGO, B.; ALBUQUERQUE, P. Paisajes transfronterizos como objeto de estudio: interés, oportunidad y complejidad en el caso de la eurorregión Alentejo - Algarve - Andalucía. IN: Colóquio Ibérico de Paisagem- O estudo e a construção da paisagem como problema metodológico. Lisboa: Universidade Nova de Lisboa, 2017a. p.119-140. 
GARCÍA FERNÁNDEZ, F.J.; ALBUQUERQUE, P.; PALMA, Mạ.F. Mértola na Idade do Ferro: primeiros resultados de dois projectos de investigação. IN: Arqueologia em Portugal 2017: Estado da questão. Lisboa: Associação dos Arqueólogos Portugueses, 2017b. p. 161-170.

GARCÍA MORENO, L.A. Hispaniae tumultus. Rebelión y violencia indígena en la España romana de época republicana. Polis, Alcalá de Henares, n.1, 1988, p 81-107.

GARCÍA TEYSSANDIER, E.; MARZOLI, D. Phönizischegräber in Ayamonte (Huelva,Spain). Einvorbericht. Madrider Mitteilungen, Mainz, n. 54, p. 89-158, 2013.

GASPAR, J. A fronteira como factor geográfico. IN: Primeras Jornadas Ibéricas de Investigadores de Ciencias Humanas y Sociales. Olivenza, 18-19-20 octubre, 1985: Acta, ponencias y comunicaciones. Salamanca: Diputación Provincial de Badajoz, 1987. p. 225-234.

GASPAR, J. Planeamento transfronteiriço e desenvolvimento regional no sudoeste comunitário. IN: CAMPESINO FERNÁNDEZ, J.; VELASCO BERNARDO, C. (Eds.). Portugal - España: Ordenación territorial del suroeste comunitario. Acta, ponencias y comunicaciones. VII Congreso Ibérico de Geografía. Cáceres: Universidad de Extremadura, 1996. p. 399-410.

GOMES, F. Aspectos do Sagrado na Colonização Fenícia. Contextos de culto de influência oriental na Idade do Ferro do Sul de Portugal (séculos VIII-III a.n.e.). Lisboa: UNIARQ, 2012.

GÓMEZ TOSCANO, F; CASTIÑEIRA, J; CAMPOS CARRASCO, J; BORJA, F.; GARCÍA, J.M. Prospección arqueológica superficial. Interfluvio Guadiana-Piedras. Anuario Arqueológico de Andalucía 1991, vol. 2, p. 239-246, 1993.

GÓMEZ TOSCANO, F; CAMPOS CARRASCO, J; BENDALA GALÁN, M. El tramo de la calzada romana Praesidio-ad Rubras del IA 23 (en la actual provincia de Huelva). IN: BUENO RAMÍREZ, P.; DE BALBÍN BEHRMANN, R. (Coord.). II Congreso de Arqueología Peninsular. Zamora: Fundación Rei Alfonso Henriques, 1999. Vol. 4, p. 237-244.

GONÇALVES, V.; ARRUDA, A.M.; CALADO, M. Novos contributos para a arqueología do Algarve oriental. Ophiussa, Lisboa, n. 0, p. 161-180, 1996.

GRADIM, A.; GRABHERR, G.; KAINRATH, B.; TEICHNER, F. O Castelinho dos Mouros (Alcoutim): um edificio republicano do Baixo Guadiana, no período de fundação da Lusitânia romana. IN: SALAS TOVAR, E. (Coord.). La gestación de los paisajes rurales entre la Protohistoria y el período romano. Mérida: CSIC, 2014. p. 45-64. Anejos de Archivo Español de Arqueología, LXX.

GRAU MIRA, I. Límite, confín, margen, frontera: conceptos y nociones en la Antigua Iberia. IN: PRADOS, F.; GARCÍA, I.; BERNARD, G. (Eds.). Confines: el Extremo del mundo durante la Antigüedad. Alicante: Universidad de Alicante, 2012. p. 23-47.

GUICHARD, F. Mettre la frontière au centre du regard. IN: GUICHARD, F.; LÓPEZ TRIGAL, L.; MARROU, L. (Coords.). Itinerarios transfronterizos en la Península Ibérica. Zamora: Fundación Rei Afonso Henriques, 2000. p. 17-20.

GUICHONNET, P.; RAFFESTIN, C.Géographie des Frontières.Paris: PUF, 1974.

HERRERO DE LA FUENTE, A.A. Veinte años de cooperación transfronteriza con Portugal. Revista de Estudios Europeos, Valladolid, v.56, p. 9-20, 2010.

HOCQUENGHEM, A.M.; DURT, É. Integración y desarrollo de la región fronteriza peruano ecuatoriana: entre el discurso y la realidad, una visión local. Bulletin de I'Institut Français de Études Andines, v. 31, n. 1, 39-99, 2002.

HOURCADE, D.; LOPES, V.; LABARTHE, J.-M. Mértola: la muraille de l'Âge du Fer. Revista Portuguesa de Arqueologia, Lisboa, v. 6, n. 1, p. 175-210. 2003.

JACINTO, R. As regiões de fronteira. IN: CAMPESINO FERNÁNDEZ, J.; VELASCO BERNARDO, C. (Eds.). Portugal - España: Ordenación territorial del suroeste comunitario. Acta, ponencias y comunicaciones. VII Congreso Ibérico de Geografía. Cáceres: Universidad de Extremadura, 1996. p. 511-521. 
JANNI, P. Los límites del mundo entre el mito y la realidad: evolución de una imagen. IN: PÉREZ JIMÉNEZ, A.; CRUZ ANDREOTTI, G. (Eds.). Los límites de la tierra: el Espacio Geográfico en las Culturas Mediterráneas. Madrid: Ediciones Clásicas, 1998. p. 23-40.

JUNTA DE ANDALUCÍA. Consejería de Obras Públicas y Transportes. Articulación territorial transfronteriza, Algarve Alentejo Andalucía: Diagnostico y estrategia para la articulación. Sevilla, 1995.

JURADO ALMONTE, J.M.; PAZOS-GARCÍA, F.J. La Frontera como Recurso Turístico. Posibilidades del Bajo/Baixo Guadiana. Revista de Estudios Andaluces, Sevilla, n. 35, p. 1-34, 2018.

LINARES CATELA, J.A. Intervención arqueológica en el Castillo de Sanlúcar de Guadiana (Huelva), $2^{a}$ fase. Trabajos arqueológicos de apoyo a la restauración. Anuario Arqueológico de Andalucía, Sevilla, 2005, vol. III, p. 1677-1695, 2010.

LOIS, R.; CARBALLO, A. La frontera hispano-lusa en la actualidad: una visión geográfica, Revista de Historiografía, Madrid, n. 23, p. 191-214, 2015.

LOPES, V. O Território de Mértola e as Vias de Comunicação no período romano. Actas das I Jornadas «As Vias do Algarve»: da Época romana à Actualidade. São Brás de Alportel: Câmara Municipal de São Brás de Alportel, 2006. p. 39-45.

LÓPEZ TRIGAL, L. La frontera como factor geográfico. IN: III Coloquio Ibérico de Geografía: Acta, ponencias y comunicaciones. Barcelona: Universidad de Barcelona, 1984. p. 596-602.

LÓPEZ TRIGAL, L. Estado de la planificación transfronteriza regional en España. IN: CAMPESINO FERNÁNDEZ, J.; VELASCO BERNARDO, C. (Eds.). Portugal - España: Ordenación territorial del suroeste comunitario. Acta, ponencias y comunicaciones. VII Congreso Ibérico de Geografía. Cáceres: Universidad de Extremadura, 1996. p. 435-441.

LÓPEZ TRIGAL, L. Centralidades y nuevas actividades en la Raya ibérica. Geopolítica(s).

Revista de Estudios sobre Espacio y Poder, Madrid, v. 7, n. 2, 181-200, 2016.

LUÍS, L. Ânforas republicanas de Mata-Filhos (Mértola). Revista Portuguesa de Arqueologia, Lisboa, n. 6, v. 2, p. 363-382, 2003.

MAIA, M. Topografia e orografia dos habitats proto - históricos do Sudoeste. IN: JIMÉNEZ ÁVILA, J. (Ed.). Sidereum Ana I: El río Guadiana en época post-orientalizante. Mérida: CSIC, 2008. p. 365-372. Anejos de Archivo Español de Arqueología, XLVI.

MÁRQUEZ DOMÍNGUEZ, J.A. La conformación de una región interfronteriza en el proyecto de Anás. IN: GUICHARD, F. (Comp.). Articulation des territoires dans la Péninsule lbérique. Bordeaux: Presses Universitaires de Bordeaux, 2001. p. 393-404.

MÁRQUEZ DOMÍNGUEZ, J.A. Dinámicas territoriales y Eurorregión en el Suroeste Peninsular. IN: MÁRQUEZ DOMÍNGUEZ, A.; GORDO MÁRQUEZ, M. (Eds.). Fronteras en movimento. Huelva, Universidad de Huelva, 2004. p. 177-197.

MÁRQUEZ DOMÍNGUEZ, J.A. (Dir.). Desarrollo en la frontera del Bajo Guadiana. Documentos para la cooperación luso-andaluza. Huelva: Universidad de Huelva, 2012.

MÁRQUEZ DOMÍNGUEZ, J.A.; JURADO ALMONTE, J.M. Los espacios de repulsión y atracción en la frontera sur - occidental hispano - portuguesa. IN: La Frontera hispano - portuguesa: nuevo espacio de atracción y cooperación. Salamanca: Fundación Rei Afonso Henriques, 2000. p. 119-134.

MARTÍN LOBO, M. Desarrollo de las regiones fronterizas hispano-portuguesas. Coloquio Nacional sobre ordenación territorial MOPU. Madrid: Dirección General de A. Territorial y Urbanismo, 1978.

MEDEIROS, E.J.R. A Cooperação Transfronteiriça na Raia Ibérica: Uma síntese geográfica dos impactes territoriais do INTERREG-A. Lisboa: Centro de Estudos Geográficos, 2009.

MELÓN JIMÉNEZ, M.A. Límites comunes, mundos distantes. Una aproximación a la historia de la frontera hispano - portuguesa. IN: Jornadas internacionales sobre la frontera hispano- 
portuguesa y sus fortificaciones: Badajoz, 8, 9 y 10 de noviembre de 2012. Badajoz: Ayuntamiento de Badajoz, 2014. p. 117-140.

MUNICÍPIO DE ALCOUTIM, Câmara Municipal. Guia do Núcleo Museológico de Arqueologia. Alcoutim: Câmara Municipal, 2011.

OSUNA LLANEZA, J.L. Estudio regional de la zona fronteriza de Huelva con Portugal. IN: SÁNCHEZ LÓPEZ, F.; CABERO DIÉGUEZ, V.; MARTÍN HERNÁNDEZ, J.T. (Ed.). Frontera y desarrollo: el programa transfronterizo de España y Portugal. Jornadas de Estudio. Salamanca: Instituto de Recursos Naturales y Agrobiología, 1993. p. 111-132.

PALMA, M. - DE F. Arqueologia urbana na Biblioteca Municipal de Mértola (Portugal) Contributos para a História local. 2009. Dissertação de Mestrado,Máster en Arqueología y Patrimonio,Universidad de Huelva, Huelva, 2009.Disponível em:http://hdl.handle.net/10400.26/2163. Acceso em: 6 ago. 2018, 18:30.

PALMA, Ma‥F. Arqueologia urbana na área de expansão da Biblioteca Municipal de Mértola. Arqueologia Medieval, Lisboa, n. 13, 5-16, 2016.

PALMA, Ma .F. (Coord.). Carta Arqueológica do Concelho de Mértola. Mértola: Campo Arqueológico de Mértola, 2012.

PECH SALVADOR, C.; RIZO GARCÍA, M.; ROMEO ALDAYA, V. El habitus y la intersubjectividad como conceptos clave para la comprensión de las fronteras internas. Un acercamiento desde las propuestas teóricas de Bourdieu y Schütz. Frontera Norte, Tijuana, v. 21, n. 41, p. 33-52, 2009.

PÉREZ MACÍAS, J.A.; REGO, L.M.V. Um povoado calcolítico junto de Mértola (Baixo Alentejo Portugal). IN: CAMPOS, J.; PÉREZ, A.; GÓMEZ, F. Arqueología en el entorno del Bajo Guadiana. Actas del Encuentro Internacional de Arqueología del Suroeste. Huelva: Universidad de Huelva, 1994. p. 149-164.

PÉREZ VILATELA L. Estrabón y la división provincial de Hispania en el 27 a.C. Polis, Alcalá de Henares, n. 2, p. 99-125, 1990.

PÉREZ VILATELA, L. Identificación diacrónica de los Cynetes en las fuentes literarias. Vipasca, Aljustrel, n. 4, p. 69-78, 1995.

PINTADO, A.; BARRENECHEA, E. La Raya de Portugal: la frontera del subdesarrollo. Madrid: Cuadernos para el Diálogo, 1972.

RAFFESTIN, C. Eléments pour une problématique des régions frontalières. Espace Géographique, Paris, n. 1, p. 12-18, 1974.

RAFFESTIN, C. Autour de la fonction sociale de la frontière. Espaces et Sociétés, Nanterre, $n$. 70-71, p. 157-164, 1992.

REGO, L.M.V.; GUERRERO, O.; GÓMEZ, F. Mértola: una ciudad mediterránea en el contexto de la edad del hierro del Bajo Guadiana. IN: Actas de las I Jornadas transfronterizas sobre la Contienda Hispano - portuguesa. Aroche: Escuela Taller La Contienda, 1996. Vol. 1, p. 119132.

RIZO GARCÍA, M.; ROMEO ALDAYA, V. Hacia una propuesta teórica para el análisis de las fronteras simbólicas en situaciones de comunicación intercultural. Estudios sobre las Culturas Contemporáneas, Colima, v. 12, n.24, p. 35-54, 2006.

RODRIGUES, S. As Vias Romanas do Algarve. Faro: Universidade do Algarve, 2004.

RUIZ ACEVEDO, J.M. Las vías romanas en la Provincia de Huelva. Huelva: Diputación de Huelva, 1998.

RUIZ RODRÍGUEZ, A.; MOLINOS, M. Las fuentes del Guadalquivir. Límites y fronteras para el norte de la Bastetania. IN: ADROHER, A.; BLÁNQUEZ, J. (Eds.). Actas del Primer Congreso Internacional de Arqueología Ibérica Bastetana. Madrid, Universidad Autónoma de Madrid, 2008. p. 51-72. Serie Varia, 9.

SAHLINS, P. Natural frontiers revisited: France's boundaries since the seventeenth century. American Historical Review, Oxford, v. 95, n. 5, p. 1423 1451, 1990. 
SÁNCHEZ LÓPEZ, F. Presentación. IN: SÁNCHEZ LÓPEZ, F.; CABERO DIÉGUEZ, V.; MARTÍN HERNÁNDEZ, J.T. (Ed.). Frontera y desarrollo: el programa transfronterizo de España y Portugal. Jornadas de Estudio. Salamanca: Instituto de Recursos Naturales y Agrobiología, 1993. p. 11-13.

SÁNCHEZ RAMÍREZ, J.; SALAS ÁLVAREZ, J. Fuentes para el estudio de la organización territorial de la Baetica en la tardoantigüedad. IN: CARBONELL MANILS, J.; GIMENO PASCUAL, h. (Eds.). A Baete ad fluvium Anam: Cultura epigráfica en la Bética Occidental y territorios fronterizos. Homenaje al profesor José Luis Moralejo Álvarez. Alcalá de Henares; Universidad de Alcalá, 2016. p. 195-225.

SOBRIDO-PRIETO, M. El tratado hispano-portugués sobre cooperación transfronteriza territorial. Anuario da Facultade de Dereito da Universidade da Coruña, A Coruña, n. 8, 839-852, 2004. SOUSA, E. Sobre o início da romanização do Algarve: 20 anos depois. Archivo Español de Arqueología, Madrid, n. 90, p. 195-218, 2017.

SOUSA, E.; ARRUDA, A.M. A gaditanização do Algarve. Mainake, Málaga, n. 32(2), p. 951-974, 2010.

TELES, P.C. Duas posições contrastadas do pensamento geográfico português sobre a teorização da fronteira luso-espanhola no início do século XX. Revista de Historiografía, Madrid, 23, p. 135157, 2015.

VEGA GONZÁLEZ, G.; ZOIDO NARANJO, F. Andalucía: cooperación transfronteriza y ordenación del territorio. IN: CAMPESINO FERNÁNDEZ, J.; VELASCO BERNARDO, C. (Eds.). Portugal España: Ordenación territorial del suroeste comunitario. Acta, ponencias y comunicaciones. VII Congreso Ibérico de Geografía.Cáceres: Universidad de Extremadura, 1996. p. 443-455. 